\title{
The detection of latent fingermarks on porous surfaces using amino acid sensitive reagents: A review
}

\author{
Renee Jelly, ${ }^{\mathrm{a}}$ Emma L.T. Patton, ${ }^{\mathrm{a}}$ Chris Lennard ${ }^{\mathrm{b}}$, Simon W. Lewis, ${ }^{\mathrm{a}^{*}}$ and \\ Kieran F. $\operatorname{Lim}^{\mathrm{c}}$ (林百君)
}

\author{
${ }^{1}$ Nanochemistry Research Institute, Department of Applied Chemistry, Curtin \\ University of Technology, GPO Box U1987, Perth, Western Australia 6845, Australia \\ ${ }^{b}$ National Centre for Forensic Studies, Faculty of Applied Science, University of \\ Canberra, Canberra, ACT 2601, Australia \\ 'School of Life and Environmental Sciences, Deakin University, Geelong, Victoria \\ 3217, Australia \\ *Corresponding Author. Email: S.Lewis@curtin.edu.au; Fax: +61 89266 2300; Tel: \\ +61892662484
}

\begin{abstract}
The introduction of ninhydrin treatment as a chemical technique for the visualisation of latent fingermarks on porous surfaces revolutionised approaches to forensic fingermark examination. Since then, a range of amino acid sensitive reagents has been developed and such compounds are in widespread use by law enforcement agencies worldwide. This paper reviews the development and use of these reagents for the detection of latent fingermarks on porous surfaces. A brief overview is provided, including an historical background, forensic significance, and a general approach to the development of latent fingermarks on porous surfaces. This is followed by a discussion of specific amino acid sensitive treatments.
\end{abstract}

Keywords: latent fingermarks, fingerprint, amino acids, porous surfaces, forensic science, review

Abbreviations: DFO, 1,8-diazafluoren-9-one; CFC 113, 1,1,2-trichloro-1,2,2trifluoroethane; HFE 7100, 1-methoxynonafluorobutane; HFE 4310mee, 1,1,1,2,3,4,4,5,5,5-decafluoropentane; IND, 1,2-indanedione, IND-Zn, 1,2- 
indanedione formulation containing zinc (II) chloride; HFE 71de, 1methoxynonafluorobutane mixed with 1,2-dichloroethylene;

\section{Table of Contents}

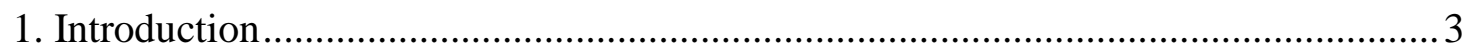

2. Latent fingermarks and their forensic significance........................................... 4

2.1 Friction ridge skin and fingermarks ........................................................ 4

2.2 Chemical composition of latent fingermarks ..................................................5

2.3 Amino acids and the detection of latent fingermarks on porous surfaces....... 7

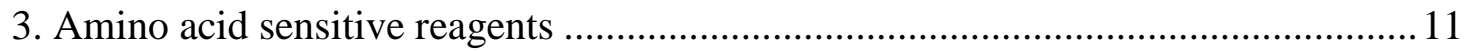

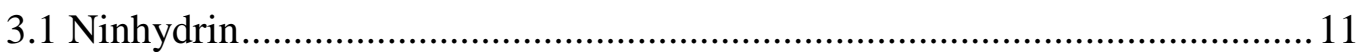

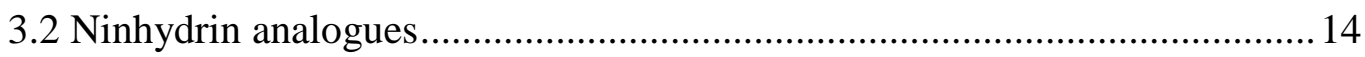

3.2.1 1,8-Diazafluoren-9-one (DFO) ..................................................... 15

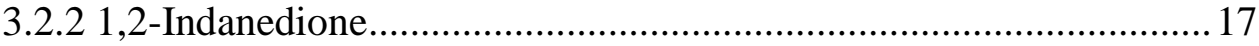

3.3 Alternative amino acid sensitive reagents ................................................21

3.4 Reagents based on natural products .......................................................21

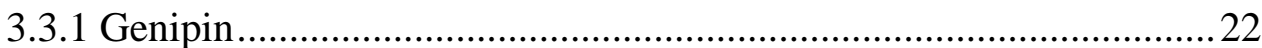

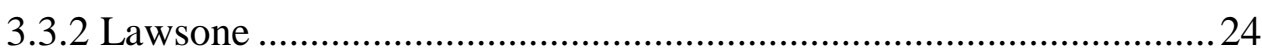

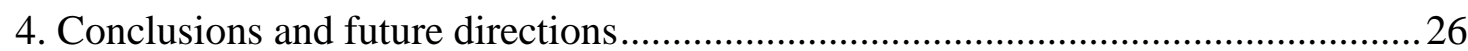




\section{Introduction}

A central tenet of forensic science is the exchange principle first proposed by Edmond Locard, which is often abbreviated to "every contact leaves a trace". Every time there is contact between persons, objects and locales there is an exchange of physical information. This is vitally important in crime scene investigation as it enables investigators to establish links between the scene, victims and the perpetrators. The impressions left by the friction ridge skin on the palmar surfaces of the hands, most often referred to as fingermarks, not only demonstrate contact but are also sufficiently unique to enable personal identification [1-3]. The most common form of these is latent (hidden) fingermarks, and successful recovery from a surface or object relies upon their detection. To this end, a range of physical and chemical methods has been developed for the visualisation of latent fingermarks [1-3]. These methods target differences between the latent fingermark and the substrate upon which it is deposited, and are based either on physical attraction or a chemical reaction [1-3].

Paper-based evidence such as documents, wrapping material and containers, are frequently encountered in criminal investigations. The most widely used methods for detecting latent fingermarks on porous surfaces rely upon the detection of the amino acids present in natural skin secretions [4-6]. When deposited on paper substrates, the amino acids are believed to bind tightly to the cellulose (provided that moisture levels are not excessive), preserving an impression of the friction ridge patterns [3]. These impressions can be very long-lived, with impressions over 40 years of age being successfully visualized [3]. The first amino acid sensitive reagent to be used for the detection of latent fingermarks was ninhydrin, which gives visible purple prints [7]. Since its introduction, there has been significant research into more sensitive treatments, which has resulted in a range of techniques used routinely by law enforcement for fingermark detection [8-10]. The detection of latent fingermarks on paper surfaces using these techniques can be considered as the trace detection of amino acids where the spatial distribution of the amino acids within (upon) the substrate needs to be retained. The intention of this paper is to provide an overview for analytical chemists unfamiliar with the area and review some recent advances in the field. 


\section{Latent fingermarks and their forensic significance}

\subsection{Friction ridge skin and fingermarks}

Skin, or the cutaneous membrane, in combination with a variety of accessory structures (hair, nails and glands), forms the integumentary system, which is the largest organ system in the human body [11]. Skin has two major components, the epidermis and the dermis [1].

The epidermis provides protection for the rest of the body from mechanical injury and from microorganisms. Depending on location, the epidermis can range in thickness from $0.08 \mathrm{~mm}$ to $0.5 \mathrm{~mm}$, with thicker skin being found on the gripping surfaces of the hands and on the soles of the feet. Beneath the epidermis is the underlying connective tissue of the dermis, within which can be found blood vessels and sensory neurons, and the various accessory structures such as hair follicles and sweat glands, which project through the epidermis to the surface of the skin $[11,12]$.

The grasping surfaces of the skin covering the fingers, palms and soles of the feet are covered in ridges and furrows, with sweat pores located along the top of the ridges. The ridges and furrows, which form characteristic patterns, develop at an early stage of gestation and have their basis in the underlying dermis [3]. Superficial damage to the epidermis will not affect them, with the patterns re-appearing on recovery. The patterns are long lived, lasting throughout the life of the individual, with only deep scar tissue potentially obscuring them. The exact shape and form of the patterns observed are controlled by both genetic and physical variables in utero, although the mechanism of their formation is not well understood [3].

The first use of impressions of friction ridge skin for identification has been a matter of some conjecture. There are indications that fingermark impressions in wax, clay and ink were used for signing legal documents in ancient Rome and the Far East. Early anatomical studies were carried out by Nehemiah Grew (1684) and Marcello Malphigi (1686), with the first major work in this area being carried out by JohanEvangelist Purkinje, who published a study on fingermark patterns, including a classification system in 1823 [13]. This study went by unremarked in the early stages 
of the introduction of fingermarks for criminal investigations. This was probably due to the limited circulation of the report and the fact that it was written in Latin [13].

The advent of the modern use of friction ridge skin impressions for law enforcement and criminal investigations was largely in the period from 1870 to 1900 . The exact course of events is complicated, and there was significant acrimony between some of the early pioneers. The interested reader is directed towards the books and articles that deal with the early history of fingermark identification and the references therein [13$18]$.

Initially, fingerprint impressions were examined as a potential method for identifying habitual criminals after arrest; however, in one of the earliest papers on the subject, Henry Faulds suggested the potential for their use in criminal investigations [19]. It was only a few years after this, in 1892, that the first recorded use of a fingermark at a crime scene occurred. The evidence enabled the conviction of Francesca Rojas in Argentina for the murder of her children $[13,14]$. Since that time, fingermarks at crime scenes have become one of the most useful tools for law enforcement in the investigation of crimes.

Impressions of friction ridge skin can be classified into two main groups, visible and latent. Visible marks occur due to the presence of a coloured contaminant on the skin (such as blood, oil or ink) giving a positive visible impression, or a coloured substance on the substrate that can be removed when touched (such as a layer of soot or dust), to leave a negative visible impression $[3,20]$. Occasionally, a visible print will be made by impression in a soft material such as clay or putty $[3,20]$. Latent, that is essentially invisible, friction ridge impressions are formed by the transfer of skin secretions and non-visible surface contaminants to the substrate $[1,3,20]$. This is the most common type of fingermark evidence found at crime scenes [1,3]. It is also the most problematic as latent fingermarks require some form of development to enable them to be visualised and recorded.

\subsection{Chemical composition of latent fingermarks}


Successful development of latent fingermarks relies heavily upon the chemistry of the latent fingermark residue itself [21]. On deposition, the fingermark can be considered to be a mixture of natural secretions - an emulsion of waxes, oils and aqueous components - and surface contaminants present on the skin surface [12,21]. With time, the chemical nature of the latent deposit will change due to evaporation of volatile components, bacterial action and oxidation [21]. The rate of change will be dependant upon the initial chemical composition of the residue and environmental conditions. This aging process can have a significant effect upon the successful development of a latent fingermark. Despite these issues, most fingermark detection techniques have been developed from the knowledge of the components of human skin secretions, without regard to the potential for aging of the print [21].

The glands responsible for the skin secretions are found within the dermis and fall into three kinds: eccrine, sebaceous and apocrine (Table 1) [11]. For the purpose of latent fingermark detection, the most important are the eccrine and sebaceous glands $[3,12,21]$. Eccrine glands are the only glands on the palms of the hands and thus contribute the major aqueous component of a latent fingermark. In addition, the hands are commonly contaminated with sebaceous secretions due to activities such as touching the face and combing the hair. Latent deposits are made up of varying combinations of secretions from these two types of gland and, while one type of secretion may predominate, there can be no purely eccrine or purely sebaceous deposit $[3,12,21]$. The composition of these secretions has been reviewed from the forensic detection standpoint and is summarized in Table 2 [3,12,21].

\section{(Insert tables 1 and 2)}

The presence of amino acids in human sweat has been widely reported in the biomedical literature (eg. [4-6,22-25]), with a wide range of amino acids being identified in human sweat (Table 3) [6]. It is known that the exact profile of amino acids present, and at what concentration, will depend upon the individual and a variety of other factors including general health, diet, gender and age [12]. This means that, whenever a new method for the detection of latent fingermarks on paper surfaces is under consideration, non-specific amino acid sensitive reagents are likely to have greater applicability [3]. 


\section{(Insert tables 3)}

\subsection{Amino acids and the detection of latent fingermarks on porous surfaces}

The amino acid component of skin secretions, and of environmental contaminants ${ }^{1}$, is extremely important when seeking latent fingermarks on paper substrates. The amino acids, when transferred to the surface of a paper substrate, will bind strongly with minimal migration provided that the surface is not wet or exposed to very high humidity [3]. Latent fingermarks formed in this way can be extremely long lived, with the authors having seen good-quality latent fingermarks in excess of 20 years of age being developed with amino acid sensitive reagents. Prior to the introduction of ninhydrin, paper documents were considered to be extremely challenging for latent fingermark detection, with limited techniques being applied (typically limited to the use of conventional fingermark powders). It would not be an understatement that the introduction of ninhydrin revolutionised this aspect of latent fingermark detection.

The use of amino acid sensitive reagents is one stage in the sequential approach taken by law enforcement in the examination of porous materials such as paper or cardboard [26,27]. The first step is a non-destructive visual examination of the evidence. If the evidence is wet, treatment with amino acid reagents is not appropriate as the amino acid component of any latent fingermarks present will have been washed away or diffused [3].

Treatment of evidence with an amino acid sensitive reagent involves dipping or spraying the item of interest with a solution of the reagent, often followed by heating [1-3]. A wide range of formulations has been proposed for the more established reagents such as ninhydrin, 1,8-diazafluoren-9-one (DFO) and 1,2 indanedione [1-3]. These formulations have generally been developed on the basis of observation and experience, although cost, health, safety and operational simplicity are also factors [1-

${ }^{1}$ One of the authors (SWL) has seen the development of very strongly coloured prints from subjects who have recently handled cooked meats, during demonstrations of fingermark detection techniques to the general public. 
3,20]. There have been wide divergences of opinion in the literature as to optimal reagent formulations and subsequent reaction conditions (see Section 3.2.2). Bramble and Brennan in 2001 suggested that a key unresolved problem in latent fingermark detection was the lack of a systematic testing regime for establishing the effectiveness of new detection methods [21]. Researchers generally use the "split print" approach, where a single fingermark is divided into two parts, which can then be treated separately with different conditions or reagents. Another approach is where a series of latent fingermarks are deposited on the surface of interest without touching anything between depositions so as to give a depletion series of prints with lower quantities of material deposited $[28,29]$. This allows some estimation of the sensitivity of the treatment. A similar approach has been used by Roux and co-workers [30-35]. Ramotowski and colleagues used the examination of naturally handled envelopes to determine the operational usefulness of 1,2-indanedione [36]. Schwarz and coworkers reported the retrofitting of an ink jet printer to print amino acids onto paper to produce standard patterns of amino acids of known concentration [37]. While this is useful as a research tool and potentially for quality assurance purposes, there is still the issue that the printer cannot reproduce the other components of a latent fingermark that may affect development.

Bramble and Brennan have summarised the key requirements of any successful fingermark visualisation reagent as being: (1) a suitable medium for the reagent; (2) a method of transport for the reagent onto or into the surface of the item of interest, and (3) provision of suitable reaction conditions [21]. Amino acid sensitive reagents are typically dissolved in a carrier solvent along with additional components such as polar solvent modifiers, acetic acid and metal salts. An ideal carrier solvent is required to be volatile enough to evaporate quickly, non-toxic, non-flammable and non-polar, so as to avoid the running of inks on treated documents. These requirements led to the widespread use of 1,1,2-trichloro-1,2,2-trifluoroethane (also known as CFC 113, Freon 113, Fluorisol and Arklone P) as a carrier solvent for ninhydrin and its analogues [2,3]. Due to its action as an ozone-depleting chemical, this solvent is no longer available for law enforcement use and alternatives such as the Freon replacement 1-methoxynonafluorobutane (HFE 7100) have been introduced [2,3]. Petroleum ether and other hydrocarbons have also been used as carrier solvents, but these are highly flammable and thus not always able to be used under normal 
operational conditions [3]. In addition to the carrier solvent, small amounts of a more polar solvent such ethyl acetate, dichloromethane, ethanol or methanol may be required to ensure that the reagents remain in solution. Depending upon the reagent, formulations may also contain other components such as acetic acid (to modify $\mathrm{pH}$ ) and metal salts (to improve development). These variations are discussed in sections 3.2.1 to 3.2.2 below.

Most reagents generally require the application of heat to develop the latent fingermark. As is the case with formulation composition, there has been a wide variety of heating regimes proposed. This heat can be applied through the use of an oven [34], domestic iron [38] or laundry press [34]. Depending on the reagent, a certain level of humidity may also be required; for example, humidity improves the development obtained with ninhydrin and genipin [2,9,39]. In some cases, such as DFO, humidity can be detrimental to successful development [40]. For some reagents it has been proposed that the heating step can be omitted, although this leads to extended development times [2,3].

The developed latent fingermark is examined and recorded photographically for subsequent fingermark identification. The exact recording conditions used will depend upon the reagent that has been used to develop the mark. While the fingermark may be visible to the naked eye under natural light (Figure 1 [41]), it can generally be enhanced by making use of the light absorbing characteristics of the developed print. Ruhemann's purple, the reaction product of ninhydrin with amino acids, has a strong absorption band at approximately $560 \mathrm{~nm}$. Ninhydrin developed fingermarks are thus best observed by illuminating with white light while viewing through a green-yellow band pass filter (Figure 2 [3]).

\section{Insert Figure 1 and 2}

An important advance for the detection of fingermarks using amino acid sensitive reagents was the advent of photoluminescence methods. It was found that ninhydrin developed marks, when post-treated with a metal salt and cooled with liquid nitrogen, exhibited photoluminescence, which could be used to significantly enhance detection sensitivity and contrast [42]. Since these early studies, the main focus of amino acid 
reagent research has been on developing reagents that exhibit good colour and superior photoluminescence without the need for additional treatments (such as metal salt treatment or cooling) [10]. Photoluminescence is observed by illuminating the developed fingermark with a filtered light source (or laser) and viewing through appropriate filters (Figures 1 and 2 and Table 4).

\section{(Table 4)}

The application of lasers to the detection of untreated latent fingermarks was first proposed by Dalrymple et al. in 1977 [43]. It was found in operational use that very few latent fingermarks exhibited native photoluminescence, however this became the starting point for the investigation of various detection techniques based on fingermark luminescence. Lasers subsequently became increasing employed in combination with latent fingermark development reagents. Herod and Menzel found that the $488 \mathrm{~nm}$ line of the argon laser was ideal for exciting the Ruhemann's purple/zinc complex ( $\lambda_{\text {ex }} 485 \mathrm{~nm}$ ) [44]. While lasers are powerful light sources for exciting treated latent fingermarks, earlier models suffered from high cost and a lack of portability. Kobus and co-workers demonstrated the suitability of a Xenon arc lamp fitted with range of filters as a light source for exciting treated latent fingermarks $[42,45]$. Since then, a wide range of non-laser light sources, collectively referred to as forensic light sources, has become commercially available and are extensively used in criminal investigations $[2,46]$. Such light sources are generally more versatile than lasers due to the wide range of wavelength bands that are available (compared to the limited number of laser lines that are typically available with laser-based systems). More recently, chemical imaging systems have been investigated for the visualization of treated latent fingermarks [31,47]. While this approach can provide significant advantages for weak marks and those on highly luminescent backgrounds, it is a very specialized technique that is generally not available to operational laboratories for routine use.

An important consideration for a fingerprint reagent or treatment is its place in the fingerprint development sequence. Items of evidence may require subsequent analysis for DNA or be subjected to document examination. Any proposed new procedure 
requires testing for its compatibility with other forensic tests [21]. It is also well established that the sequential use of specific amino acid sensitive treatments will result in the detection of more fingermarks [27]. Research at the Central Research Establishment in the UK found that treatment with ninhydrin after DFO resulted in up to $10 \%$ more marks being developed than with DFO on its own. This result was confirmed by a national field trial held in Canada [48]. Use of ninhydrin before DFO resulted in no further marks being developed [27]. Research of this nature has resulted in the publication of recommendations of reagent sequences [26,27]. These recommendations will give satisfactory results in $70-80 \%$ of cases, and may require modification in some circumstances depending on the nature of evidence being examined [3]. In addition, as indicated by Lee and Gaensslen, these sequences need to be under constant review as new reagents and treatments are developed, as even subtle changes in formulation or treatment conditions may have an effect on the performance of a reagent in a sequence [20]. In a recent study, Wallace-Kunkel and co-workers determined that no advantage was gained by using 1,2-indanedione in sequence with ninhydrin compared with the use of 1,2-indanedione on its own. This was in contrast to earlier studies and was thought to be due to the differences in reagent formulation used [34].

\section{Amino acid sensitive reagents}

\subsection{Ninhydrin}

Ninhydrin is recognised as the predominant reagent for the visualisation of latent fingermarks on porous surfaces to aid criminal investigations [49-52]. On reaction with amino acids, ninhydrin (2,2-dihydroxy-1,3-indanedione) forms a non-fluorescent purple product. The reagent was first synthesised and discovered to react with amino acids in 1910 by Siegfried Ruhemann. A colour change was observed after the reagent contacted his skin, with the formation of a purple compound that was subsequently named "Ruhemann’s purple” [49,52]. It took until the mid 1950s before the suggestion was made, by Oden and von Hofsten, that ninhydrin could be used as a means to detect latent fingermarks on porous substrates [7]. 
Ninhydrin has now become the most extensively publicised and researched amino acid visualisation reagent [53]. Initial debates in relation to the types of amino acids responsible for this purple formation are well documented. Some indicated the involvement of all amino acids, whereas others reported that only alpha amino acids were reactive in this way. Collective opinions suggested the likelihood that the purple colour was the same irrespective of the amino acid. This was after indications that only a fragment of the amino acid (the nitrogen of the amino group) is featured in the structure of Ruhemann's purple [2,54]. The accepted general mechanism for the ninhydrin reaction was proposed by Friedman and Williams in 1974 [55] and was confirmed, with slight modifications, by Grigg and colleagues with the use of x-ray studies [52,56]. The most documented proposal involves a Strekker degradation where reduction of a carbonyl on indanetrione forms 2-amino-1,3-indanedione (II in Scheme 1) by means of a resonance stabilised azomethine ylide. The 2-amino-1,3indanedione can then react with another indanetrione molecule to form the stable 1,3dipole Ruhemann’s purple [2,56-58].

\section{(insert Scheme 1)}

Despite ninhydrin's operational success with respect to developing latent fingermarks on porous surfaces, several limitations became apparent. Of particular importance was the lack of contrast and sensitivity observed which was resolved with the introduction of a secondary metal salt treatment and the use of lasers and alternate light sources. Previous studies involving separation of amino acids by thin layer chromatography using ninhydrin as a visualising agent had utilised an additional treatment with particular metal salts which resulted in a colour change to red or orange (Figure 2) [2].

Fingermark chemists in turn looked at this as a means to overcome any potential contrast issues, in particular with coloured substrates, and also found evidence of improved stability of the coloured product [2]. In 1982, Herod and Menzel, who investigated this concept, not only found that fingermarks underwent a colour change with a post-treatment using zinc chloride but also observed intense fluorescence when viewed under an argon laser [44]. Kobus and co-workers indicated the importance of cooling with liquid nitrogen (77K) to observe luminescence when excited using 
illumination from a filtered Xenon arc lamp. Ruhemann's purple forms a coordination complex with the metal salt changing the colour of the compound. The colour change observed is due to energy transitions of electrons in the $d$ orbitals of the transition metal. The increased rigidity of the pi system in the Ruhemann's purple metal ion complex is thought to cause the observed luminescence. This effect is further enhanced when cooled with liquid nitrogen. This provides a similar outcome to the use of an argon laser and serves as an alternative to law enforcement agencies that lack funding or access to an argon laser [42].

Photoluminescence characteristics are valuable in analytical chemistry due to increased sensitivity resulting in improved detection limits. When applied to fingermark chemistry, this allows for excellent contrast, offering fingermarks with intense luminescence and minimal background interference $[2,59,60]$. The luminescence characteristics observed for the Ruhemann’s purple - metal ion complex is dependent on the type of metal salt used; for example, when using zinc chloride as the post-treatment, the excitation maximum is at $495 \mathrm{~nm}$, with an emission maximum of $540 \mathrm{~nm}$ [26]. Ruhemann's purple is known to be an active chelating agent that readily forms coordination complexes with certain metal ions [61]. The accepted structure of the Ruhemann's purple metal complex, as shown in Scheme 1-b, was first determined by Lennard and colleagues with the use of X-ray diffraction [61]. This was verified via single crystal x-ray diffraction studies conducted by Davies and co-workers [62,63].

A large body of work has been carried out into the optimal developmental conditions for ninhydrin [2,3,64-67]. The formation of Ruhemann's purple has a slow reaction rate, which can be accelerated with the application of heat. Heat application is not generally recommended because ninhydrin may react with particular additives incorporated in the paper. The application of heat will speed up both the desired and undesired processes, resulting in a degradation of contrast and a potential destruction of any fingermark evidence. As this undesired side-reaction is considered to be slower than the reaction that takes place with amino acids, it is preferable to monitor the reaction without the application of heat to ensure that any developed marks are recorded immediately and before background staining becomes problematic [26]. Along with this, the developmental conditions, such as temperature, acidity $(\mathrm{pH})$ and 
humidity, must be controlled to ensure optimal production of the coloured product. Generally the formulation consists of a final concentration of approximately $0.5 \% \mathrm{w} / \mathrm{v}$ ninhydrin, with fingermark development allowed to progress at room temperature over a $24-48$ hour period in an environment with $50-80 \%$ relative humidity $[1,61]$.

\subsection{Ninhydrin analogues}

The discovery of ninhydrin as an effective fingermark detection reagent prompted further investigations into ninhydrin analogues. This was based on the awareness that Ruhemann's finding was serendipitous, not on the basis of chemical knowledge and theoretical design. Along with this, the issues with contrast and visualisation could not be overcome by simple modification of the ninhydrin formulation and working conditions. This sparked fingermark chemists to investigate various molecules that possessed similar structural features that were responsible for the formation of Ruhemann's purple [2,52]. In 1982, Almog and colleagues were the first to apply this methodology as a means to improve the visualisation properties with respect to fingermark detection. In principle, the inclusion of electron donating and/or electron accepting substituents alters the electronic properties of the conjugated system, to produce variations in colour and/or photoluminescence. The general consensus was to develop specifically coloured complexes that could be applied to aid visualisation on a variety of backgrounds - in particular, backgrounds notorious for being problematic with conventional ninhydrin treatment [2,52]. Many ninhydrin analogues were synthesised and have been studied, some of which are shown in Figure $3[51,52,68]$.

\section{(insert figure 3)}

Some of the analogues in Figure 3 showed promise, with both improvements in visualisation and variation in colour and luminescence [2]. The most prominent ninhydrin analogues, which surpassed initial expectations, were 1,8-diazafluorene-9one (DFO) and 1,2-indanedione. These were of particular interest because they produce both colour and intense luminescence on reaction with the amino acids in latent fingermarks, without further treatment. 


\subsubsection{1,8-Diazafluoren-9-one (DFO)}

DFO was first synthesised by Druey and Schmidt in 1950 [69] and introduced as a fingermark reagent by Grigg and Pounds in 1990 [70,71]. On reaction with amino acids, DFO forms a red product that is luminescent $\left(\lambda_{\text {ex }} 430-580 \mathrm{~nm}, \lambda_{\text {em }} 560-620 \mathrm{~nm}\right.$ [3]) when viewed under a laser [40] or an alternate light source [72]. Isolation and identification of the luminescent product has been carried out and, even though DFO is not a direct analogue of ninhydrin, it is thought to react with amino acids in a similar fashion (Scheme 2) [30,70,71,73]. Initially, DFO reacts with the amino acid to form an imine (I), which undergoes decarboxylation and hydrolysis to form an aromatic amine (II). This amine then reacts further with an excess of DFO to produce a red product (III) [73]. Unlike the ninhydrin reaction, for this reaction to proceed heat must be applied using either an oven $\left(20 \mathrm{~min}\right.$ at $100^{\circ} \mathrm{C}$ [3]) or a dry heat/ironing press (10 sec at $180^{\circ} \mathrm{C}$ [72]). It is important to note that prolonged heat, high temperatures and humidity should be avoided as they have a detrimental effect on the luminescence of developed marks [38,40].

\section{(insert Scheme 2)}

DFO treatment affords developed fingermarks that are strongly luminescent without any secondary treatment or reduction in temperature. Observation in the luminescence mode provides greater detection sensitivity than can be obtained with ninhydrin [1,7072,74]. In the absorption mode, ninhydrin developed fingermarks possess greater contrast compared to the pale red/purple colour obtained using DFO [34,70,72]. It has been suggested that the weak red/purple colour is produced by the incomplete or slow reaction of DFO with the amino acids found in latent deposits [28,52]. Therefore, it is recommended that the colour of weakly developed fingermarks should be further enhanced by treatment with ninhydrin if necessary, particularly if background luminescence precludes detection in the luminescence mode $[40,75]$.

Even though DFO was found to produce intensely luminescent fingermarks, research continued to investigate the enhancement of both sensitivity and contrast of the reagent. One approach, in a similar manner to ninhydrin, was to investigate the addition of metal salts. Conn and co-workers investigated the effect of zinc, cadmium, 
ruthenium and europium on the luminescence of DFO treated fingermarks. They found that, while metal salt treatment showed no significant increase in the luminescence, a change in the colour of the product was observed with all but europium [30]. This suggests that, as with ninhydrin, the metal salts form a complex with the reaction product, thus changing its colour.

Since the introduction of DFO as a routine fingermark detection method, the precise formulation of the reagent has varied significantly [26,40,70,72,75-77]. The initial formulation suggested by Pounds and colleagues contained methanol, acetic acid and CFC 113, which was found to be unstable and the large amount of methanol caused the running of some inks on cheques [70]. While methanol is primarily used to dissolve DFO in the non-polar carrier solvent, it has been shown to be a necessary component of the DFO formulation as it causes the formation of a reactive hemiketal [73]. Stoilovic and co-workers found that a formulation with a final polar solvent concentration below $10 \%$ would not cause any significant dispersion of writing inks on treated documents [72].

Improvements on the early formulation were made by Hardwick and colleagues that resulted in a formulation that was stable for months and was simple to prepare [75] when compared to the petroleum ether/xylene formulation suggested by Masters et al. [40]. While CFC 113 was considered the best carrier solvent for DFO, environmental concerns prompted the search for new, safer carrier solvents. Diderjean and coworkers found that a formulation where CFC 113 was replaced with HFE 7100 developed fingermarks that were of equal or better quality than those developed with a CFC 113 based formulation [76]. The current formulation recommended by the Australian Federal Police contains 0.72 g/L DFO, 9\% polar solvent (dichloromethane, methanol and acetic acid) in HFC 4310mee (1,1,1,2,3,4,4,5,5,5-decafluoropentane) [26].

Typically, DFO is applied to a substrate by dipping in the reagent solution, air drying, and heating in either an oven or ironing press. In order to combat problems with particular carrier solvents (eg. environmentally damaging, flammable, or causing ink to run), a new method of applying DFO to the substrate - referred to as "DFO-Dry" was investigated by Bratton and Juhala [78]. This technique involved the application 
of DFO from soaked filter papers by processing with a steam iron filled with a 5\% acetic acid solution before heating at $100^{\circ} \mathrm{C}$ for 10 minutes. "DFO-Dry" does not use any heptane, petroleum ether, or CFC 113 in the working solution. The advantages of this method are reported to be equal luminescence in developed marks compared to conventional techniques without background induced luminescence or any ink migration, and the "working papers" can be prepared in advance and reused several times [78].

\subsubsection{1,2-Indanedione}

Joullié and colleagues first publicised, in 1997, the ability of 1,2-indanedione to react with the amino acids present in latent fingermarks [51,79]. Since that time, significant research has been undertaken into the use of 1,2-indanedione as a fingermark detection reagent. Similar to DFO, the reaction between $\alpha$-amino acids and 1,2indanedione results in a pale pink colour with intense room-temperature luminescence $[8,51,79,80]$. Studies into the mechanism of the reaction of 1,2-indanedione and amino acids suggest that it reacts initially with amines to form imines (I in Scheme 3) $[57,80,81]$, which is then followed by decarboxylation and Strekker degradation to produce 2-amino-1-indanone (II). This can then react further with an excess of 1,2indanedione to produce a coloured and luminescent species (III) [57]. Although proposed, the reaction product has yet to be isolated and its structure confirmed.

\section{(insert Scheme 3)}

As 1,2-indanedione is similar in structure to ninhydrin, treatment of the reaction product with metal salts has been investigated [32,34,51,79]. When 1,2-indanedione developed fingermarks were treated with zinc or cadmium chloride, the luminescence intensity of the reaction product was increased $[32,34,51,79]$ and the colour of the product became a darker pink, improving contrast [34]. This also occurred when the zinc salt was added to the solution of 1,2-indanedione [33,51]; this was reported to decrease the shelf-life of the reagent [51]. Recent investigations have determined that the shelf-life of a revised 1,2-indanedione formulation is not adversely affected by the addition of a metal salt [34] and the development of fingermarks using a combined 1,2-indanedione/zinc (II) (IND-Zn) formulation is less reliant on ambient humidity 
[33]. The exact role of the metal salt in the 1,2-indanedione reaction has yet to be clarified but is the focus of current investigations.

Early studies showed that fingermarks treated with 1,2-indanedione alone decomposed within a few days, to lose both their colour and luminescence [51]. Those treated with IND-Zn had increased longevity, taking weeks or months to lose their colour and luminescence [51]. In 2003, Gardener and co-workers investigated the stability of 1,2-indanedione treated fingermarks when exposed to daylight for extended periods of time. They found that samples left in daylight for 28 days degraded to only $20 \%$ of their original luminescence, and samples excluded from light had increased longevity. They also found that post-treatment of the sample with zinc chloride did not slow down the degradation, and suggested that photolysis of the product was the cause of the degradation [82].

Since the discovery of 1,2-indanedione, there have been inconsistencies in the literature concerning the optimal working formulation for the development of latent fingermarks [28,32-34,77,82-86]. Early investigations used methanolic solutions, although it is now recommended to limit the amount of the alcohols in 1,2indanedione solutions as they form hemiketals that interfere in the reaction with amino acids $[28,57,87]$. In addition, methanolic solutions were believed to be responsible for the smudging of developed fingermarks [32]. Roux et al. investigated the effect of different carrier solvents (CFC 113, methanol, petroleum ether, HFC 4310mee and HFE 7100) on the development of latent fingermarks. They found that HFE 7100 and HFC 4310mee produced more intense luminescence than petroleum ether and CFC 113, with HFE 7100 showing the most promising results [32]. Wallace-Kunkel and co-workers also investigated the different carrier solvents HFE 7100, HFC 4310mee and HFE 71de (1-methoxynonafluorobutane mixed with 1,2dichloroethylene) as replacements for petroleum ether. The results showed that HFE 7100 was superior to the other solvents, providing better results with lower health and safety risks [34]. Studies conducted by Bicknell and Ramotowski found that a petroleum ether based formulation developed fingermarks that were darker in colour and showed stronger luminescence than a HFE 7100 formulation [36]. 
There has also been some disagreement in the literature concerning the necessity of acetic acid in the 1,2-indanedione formulation. It was assumed that, as the ninhydrin reaction requires a slightly acidic environment $[66,88]$, so too would 1,2-indanedione. Wiesner and colleagues investigated the influence of $\mathrm{pH}$ on this reaction and reported that better results were obtained using a formulation without acetic acid [28]. However, acetic acid is still considered by most research groups to be an important component of the 1,2-indanedione formulation and its use is widespread. It has been found that relative humidity and moisture content of the paper affects the reaction of 1,2-indanedione with amino acids in fingermarks $[33,34,86]$. This may account for the observed differences in the literature due to variation in climatic conditions of countries where research has been carried out. Unlike DFO, heating of 1,2indanedione treated latent fingermarks is not necessary as they may develop at room temperature over 24 - 48 hours [32]. The 1,2-indanedione reaction can be accelerated by heating with either an oven or dry heat/laundry press [32,34]. Both Roux et al. and Wallace-Kunkel et al. found that heat applied with a laundry press provided better luminescence than oven heating [32,34]. For optimum development, it is recommended that 1,2-indanedione treated fingermarks are heated with a laundry press at $160-165^{\circ} \mathrm{C}$ for 10 seconds [26].

It is generally agreed that, when only using white light to visualise treated latent fingermarks, ninhydrin is more advantageous than both 1,2-indanedione and DFO due to a deeper colouration, which produces better contrast. It is also agreed that, when viewing treated fingermarks under a forensic light source in the luminescence mode, both DFO and 1,2-indanedione are more sensitive than ninhydrin with metal salt posttreatment [32,34]. There are inconsistencies as to whether 1,2-indanedione shows superior fingermark development compared to DFO [8,28,32-34,36,51,77,82,89]. Here, the meaning of 'superior development' is twofold: (i) whether a reagent develops more fingermarks that are identifiable; and (ii) whether the resulting fingermarks show an enhanced appearance in both the absorption and luminescence modes. Merrick and co-workers reported that 1,2-indanedione developed fewer identifiable latent fingermarks than DFO [77]. In a similar fashion, a national field trial conducted in Canada found DFO performed better than the formulation of 1,2indanedione used [89]. In contrast other studies have found that 1,2-indanedione developed substantially more latent fingermarks than DFO or DFO followed by 
treatment with ninhydrin [28,34]. Recent investigations report that IND-Zn produces a greater number of identifiable fingermarks than DFO [33]. Gardner and colleagues reported that DFO treated latent fingermarks are more luminescent than those treated with 1,2-indanedione [82]. This statement is supported by Roux and colleagues findings that 1,2-indanedione only produced fingermarks that were more luminescent than DFO after post-treatment with a metal salt and cooling [32]. On the other hand, Wallace-Kunkel and co-workers found that 1,2-indanedione produces more luminescent fingermarks [34]. More recent research conducted in Australia and the United States has found that IND-Zn develops fingermarks that are deeper in colour and more luminescent than DFO [33,36]. These discrepancies could be caused by differences in the 1,2-indanedione formulations and development conditions used in each of the studies (eg. presence or absence of zinc, reagent concentrations, solvent mixture, oven versus heat press development, etc.).

As described above, there remains a wide variation in views as to the optimum conditions and relative performance of the various formulations proposed for 1,2indanedione and DFO. These variations are in all likelihood due to the local environment and the substrates under investigation, as well as the many minor variations in reagent formulation. A reagent that works best under one set of conditions (formulation, environmental factors, substrates, etc.) may not be the best reagent under another set of conditions (eg. different country, different climate, different substrates). This would then explain why DFO appears better in UK studies (and to some extent in Canada), while 1,2-indanedione appears better in Australia (and Israel). This was highlighted in a recent study by Spindler et al. who reported spectral variations for the reaction products of ninhydrin, DFO, indanedione and indanedione-zinc reagents with amino acids on cellulose based substrates [90]. It is the authors' belief that, on this basis, there cannot be a single global optimum for any of the discussed fingermark treatments.

As with DFO, the position of 1,2-indanedione in the sequence of reagents for use on porous surfaces has been examined [32,34]. Preliminary studies by Roux and colleagues concluded that 1,2-indanedione gave marginal advantages when used in sequence with DFO and gave inferior results to ninhydrin or 1,2-indanedione alone when used in sequence with ninhydrin [32]. A study conducted by Wallace-Kunkel et 
al. in 2007 reports contradictory findings. They found that when 1,2-indanedione is used after ninhydrin there is no change in the development of latent fingermarks. When ninhydrin is used after 1,2-indanedione the developed fingermarks become darker in colour. It is suggested that this is due to the incomplete reaction of 1,2indanedione with amino acids, as is the case with the DFO-ninhydrin sequence (previously discussed in section 3.2.1). It was also found that, when 1,2-indanedione was used in sequence with DFO, there was no change to the developed fingermarks. The authors suggest that 1,2-indanedione or DFO be used prior to ninhydrin treatment [34]. Currently, the Australian Federal Police recommends the use of ninhydrin after development with 1,2-indanedione [26], particularly where background luminescence interferes with the visualisation of developed fingermarks.

\subsection{Alternative amino acid sensitive reagents}

With a greater understanding of fingermark chemistry and the introduction of lasers and other forensic light sources, research into chemical alternatives to ninhydrin and its analogues for amino acid detection have also been explored. Reagents that demonstrated the greatest prospects were fluorescamine, o-phthalaldehyde and NBDchloride (7-chloro-4-nitrobenzo-2-oxa-1,3-diazole) [20,45]. However, these reagents have not come into operational use due to disadvantages when compared to ninhydrin and its analogues. Fluorescamine and o-phthalaldehyde react with amino acids to form products that are luminescent under UV light and thus their application is limited due to interference from the UV elicited photoluminescence from the optical brighteners present in many paper substrates [20]. The products of the reaction of NBD-chloride with amino acids exhibit luminescence when excited in the visible region. However, NBD-chloride lacks specificity as it reacts with other unidentified components present in some paper substrates leading to background luminescence and reduced contrast [20]. In addition, NBD-chloride only gives products that are visible when viewed with a suitable light source [20].

\subsection{Reagents based on natural products}

Prior to 2004, research into non-specific amino acid targeting reagents primarily focused on ninhydrin and related compounds. An alternative research path developed 
with the discovery of genipin (Figure 4) [9], which, unlike other reagents, was not synthesised as a ninhydrin analogue. Thus began a new trend into researching natural products for fingermark detection applications.

\section{Insert Figure 4}

\subsubsection{Genipin}

In 2004, Almog and colleagues were first to recognise the significance of genipin as an amino acid targeting “dual” fingermark reagent. Genipin is colourless until reaction with primary amino acids, which results in the formation of a blue colour with luminescence characteristics $\left(\lambda_{\mathrm{ex}} 590 \mathrm{~nm}, \lambda_{\mathrm{em}} 620 \mathrm{~nm}\right.$ ) without further treatment. Furthermore, the safety, simplicity and sensitivity involved in detecting fingermarks using genipin adds to its potential as a fingermark reagent [9,91].

Genipin is obtained from a number of different plant sources including Gardenia jasminoides Ellis and Genipa Americana. Extracts from these plants have been used for centuries as a traditional Chinese medicine, food and fabric colorants and as skin dyes $[92,93]$. Herbal medicines are available as an alternative to western medicines and are often considered to be non-toxic [94]. For this reason, genipin is considered chemically safe and less hazardous than other common fingermark reagents [9,91,93].

Genipin's ability to stain the skin was first reported in the chemical literature by Djerassi and colleagues in 1960, who published that "genipin itself is colourless, but if brought to the skin, it rapidly produces an indelible bluish/violet colour.” They later established genipin's ability to rapidly react with amino acids $[91,95,96]$. Along with this, they describe Oviedo's recollection of how the Indians in the $18^{\text {th }}$ century bathed in the clear juice of the fruit when tired and as a means for painting their skin, implying the use of genipin not only as a therapeutic remedy but also as a form of adornment [95].

Genipin has been of particular interest in the food industry. With growing concerns over the health and safety of synthetic dyes, the importance of natural colorants in foodstuffs has gained increasing attention. The only natural blue coloured pigments 
known to be available are obtained from Gardenia fruits and from algae [93]. However, the protein dye, phycocyanin, derived from algae, becomes unstable when subjected to the common conditions associated with food manufacturing and processing [93,97]. This prompted further investigations by Paik and co-workers on the stability of genipin. They found that the Gardenia blue pigments were very stable with regards to environmental factors, such as $\mathrm{pH}$, high temperatures and exposure to light [93].

In the biomedical community, genipin has become a molecule of interest as it is a naturally occurring, biocompatible molecule with low cytotoxicity. Research has found that it has the ability to form crosslinking networks with important biological polymers preventing degradation [92,98,99]. Intramolecular and intermolecular crosslinks are formed with compounds containing a primary amine group and, as a result, genipin can be used as a bioadhesive, which aids healing after surgery [100$102]$, as a bone substitute $[103,104]$ and as a conduit material for peripheral nerve regeneration [105].

It is the ability of genipin to react with amine groups to form intensely coloured dyes, coupled with its low toxicity, that has given genipin the potential to provide operational advantages over current fingermark reagents. Almog and colleagues found that the resulting photoluminescence emits at longer wavelengths than currently observed for other fingermark reagents [9,91]. This can result in an improved signalto-noise ratio due to the shift away from any potential background fluorescence, creating greater contrast between the fingermark and the substrate [91]. Due to the novel nature of genipin as a latent fingermark developer on porous surfaces, implementation for routine forensic use, at this stage, could be somewhat premature [9]. With further optimisation and development, the use of genipin may become an important technique to aid in the development of latent fingermarks on porous surfaces, particularly on substrates where background luminescence is problematic.

One key area of research is focussing on determining the reaction mechanism and the resulting chromophore and/or fluorophore, which has yet to be verified. Investigations have been conducted looking at the reaction of genipin with simple compounds containing primary amines, which in turn indicate the formation of heterocyclic 
amines. These amines were further associated to form cross-linking networks, containing short chain dimer, trimer and tetramer bridges [92,98,106,107].

Additionally, the reaction of genipin with amino acids has been reported to produce more than one coloured compound $[91,108]$. Touyama and colleagues reported the presence of one yellow and 9 brownish-red pigments (A-I), which were proposed to be precursors of the blue product(s). It was presumed that the blue product(s) was formed through oxygen radical-induced polymerisation and dehydrogenation of a mixture of intermediary pigments as depicted in Figure 5 [109,110].

\section{(insert figure 5)}

Alternatively, Fujikawa proposed that a monomeric adduct, genipocyanin, was formed from genipin reacting with glycine which further crosslinked to proteins $(\mathrm{R}$ in Figure 6-b) [106]. Although structural similarities are present between compounds in Figure 6 and Touyama's postulations featured in Figure 5, significant conformational variations exist, exemplifying the difficulty in deducing the mechanism involved. These investigations by Fujikawa and Touyama were carried out in solution phase, which may not give a true representation of the mechanism involved on paper substrates. When amino acids from a fingermark bind to a substrate, the concentration or surface coverage is such that the amino acids are well separated. Hence the lack of mobility means that oligomeric products derived from multiple amino acid units are highly unlikely. In solution, however, the ability of amino acid and genipin units to mix permits the formation of products involving multiple amino acid and genipin units. Unpublished work by Fazendin provides LC-MS evidence for the formation of products involving more than 8 amino-acid-genipin units when the reaction is conducted in solution [111]. The exact nature of the reaction occurring between genipin and latent fingermark deposits, the nature and the number of products formed in the reaction on paper substrate is thus still yet to be established.

\section{(insert Figure 6)}

\subsubsection{Lawsone}


With the successful assessment of genipin as a potential amino acid targeting reagent, attention was directed towards other possible natural products associated with or displaying dying qualities. One of the most frequently used natural dyes is henna. Henna is sourced from the leaves of Lawsonia Inermis and is commonly used to temporarily dye the skin and hair $[112,113]$. As with genipin, indigenous cultures used henna as part of religious, social and ritualistic traditions, the most prominently recognised being mehndi decorations. This tradition consists of intricate designs drawn in henna as a temporary form of body art and is applied to brides before their wedding ceremonies [113]. The first use of henna as a hair dye can be traced back to at least 4000 years ago as hair from Egyptian pharaohs contained evidence of henna [114].

Lawsone (2-hydroxy-1,4-naphthoquinone) is believed to be the molecule responsible for the dying quality of henna [112,113]. In 2008, Jelly and co-workers reported on the reaction of lawsone with primary amino acid residues on paper surfaces. The reaction was found to produce a dark purple/brown compound that also exhibited photoluminescence without further treatment [41]. In a similar manner to genipin, lawsone has a maximum intensity of luminescence occurring around $640 \mathrm{~nm}$ with excitation at $590 \mathrm{~nm}$. This is operationally significant as photoluminescence emission at longer wavelengths has the potential to improve detectability by avoiding any native background interference. Nevertheless, due to the novel nature of this work, there is a significant amount of additional research required in order to assess the potential of lawsone as a tool for developing latent fingermarks on porous surfaces [41]. The reaction mechanism must be reviewed in order to obtain some level of understanding as to the way in which the chromophore/fluorophore is produced. This, in turn, will allow for an accurate assessment of the effectiveness of lawsone as a fingermark reagent. Jelly and colleagues postulate the formation of a diametric product that is based on Spyroudis's review on the reactivity of hydroxyquinones (Scheme 4). This mechanism is similar to the ninhydrin reaction with amines and amino acids; unlike ninhydrin, lawsone does not require further treatment with a metal salt to form a luminescent product $[41,115]$.

\section{(insert Scheme 4)}


Naphthoquinones are a class of compounds that are well known for their bioactivity $[116,117]$ and their ability to react with amino groups have been extensively reported [115,118-129]. 1,2-naphthoquinone-4-sulfonate has been employed for the determination of amino acids through the formation of highly coloured compounds [130-134]. Rees and colleagues specifically studied the use of 1,2-naphthoquinone to form a purple/brown compound on reaction with cysteine, and also noted that the reaction was believed to target the amino group of the amino acid [135]. This provides strong evidence to suggest the importance of naphthoquinones for the detection and colorimetric analysis of primary amines or associated compounds and, in turn, their potential use for detecting latent fingermarks on porous surfaces.

\section{Conclusions and future directions}

Given the value of fingerprint evidence in criminal investigations and the proven benefits that come from targeting the amino acids in the deposit, active research in this area will continue into the foreseeable future.

The main thrust of this research is likely to remain focussed on increasing the likelihood of detecting and recording weak latent fingermarks on porous surfaces. This search for improved selectivity and sensitivity is shared with other areas of analytical chemistry. Despite ninhydrin being the predominant reagent for targeting the amino acids present in fingermark residue, there has been significant research to discover new reagents that offer operational advantages. This search for increased sensitivity, with a preference for luminescence detection, has focussed on the synthesis and optimisation of ninhydrin analogues. New directions will need to be taken to open up other pathways to candidate reagents. There is a recent trend to investigate natural products as a means of targeting the amino acids in latent fingermarks, with associated benefits such as possible reduced toxicity. There is a huge range of natural products yet to be investigated for their potential to react with amino acids and provide a means for detecting latent fingermarks on porous surfaces.

In addition to the discovery of new reagents, there is still a need for further research to gain a better understanding of the reaction mechanisms associated with established reagents (eg. DFO and 1,2-indanedione) and those still under development (eg. 
genipin and lawsone). There are still unanswered questions as to the exact role of certain components within formulations, such as metal salts. These studies will need to utilise surface analysis techniques in order to examine the reaction intermediates and products in situ rather than in solution in order to obtain results that are applicable to fingermark detection on porous substrates. A better understanding of reaction mechanisms will potentially allow the design of amino acid reagents with enhanced properties.

On an operational level, there is a requirement for more standardised approaches to determine the performance of latent fingermark treatments as a whole. This could involve a collaborative trial approach to examine the variations noted in section 3.2.2 for "optimum" conditions for the various fingermark visualisation reagents. At this time, there is no agreement as to what would constitute a "standard" latent fingermark. Fundamental studies of the latent fingermark residue in situ, including aging studies, would aid this area of research. While there have been a number of reports in the literature regarding chemical analysis of the fingermark residue [136139], most have tended to involve removal of the residue from the surface, thus losing any potential spatial information on the distribution of chemical species.

Continued research in this field will require expertise in chemical synthesis, materials science and advanced spectroscopy, and thus there is ample room for analytical chemistry researchers to help improve and extend a key forensic technique.

\section{Acknowledgements:}

The authors would like to thank Dr David Brown and Lisa Swann (Curtin University of Technology) for reviewing the manuscript prior to submission and Yvonne Fazendin (Deakin University). We would also like to thank Dr Della Wilkinson (Royal Canadian Mounted Police, Forensic Identification Research Services) for help in sourcing papers. RJ is supported by a Curtin University Postgraduate Scholarship and ELTP by an Australian Postgraduate Award.

\section{References:}


[1] J. Almog, FINGERPRINTS (DACTYLOSCOPY): Visualization in: J. Siegel, P. Saukko, G. Knupfer (Editors), Encyclopedia of Forensic Sciences, Academic Press, Oxford, 2000.

[2] J. Almog, Fingerprint Development by Ninhydrin and Its Analogues in: H.C. Lee, R.E. Gaensslen (Editors), Advances in Fingerprint Technology, Second Edition, CRC Press, Boca Raton, 2001.

[3] C. Champod, C. Lennard, P. Margot, M. Stoilovic, Fingerprints and Other Ridge Skin Impressions, CRC Press, Boca Raton, 2004.

[4] C.A.J. Coltman, N.J. Rowe, R.J. Atwell, Am. J. Clin. Nutr., 18 (1966) 373378.

[5] B. Hadorn, F. Hanimann, P. Anderson, R. Halverson, Nature, 215 (1967) 416417.

[6] P.B. Hamilton, Nature, 205 (1965) 284-285.

[7] S. Oden, Nature, 173 (1954) 449-450.

[8] J. Almog, E. Springer, S. Wiesner, A. Frank, O. Khodzhaev, R. Lidor, E. Bahar, H. Varkony, S. Dayan, S. Rozen, J. Forensic Sci., 44 (1999) 114-118.

[9] G. Levinton-Shamuilov, Y. Cohen, M. Azoury, A. Chaikovsky, J. Almog, J. Forensic Sci., 50 (2005) 1367-1371.

[10] J. Almog, G. Levinton-Shamuilov, Y. Cohen, M. Azoury, J. Forensic Sci., 52 (2007) 330-334.

[11] F.H. Martini, Anatomy and Physiology, Pearson, Benjamin Cummings, San Francsico, CA, 2005.

[12] R. Ramotowski, Composition of Latent Print Residue in: H.C. Lee, R.E. Gaensslen (Editors), Advances in Fingerprint Technology, Second Edition, CRC Press, Boca Raton, 2001.

[13] C.J. Polson, J. Crim. Law. Criminol. (1931), 41 (1950) 495-517.

[14] P. Margot, HISTORY: Fingerprint Sciences in: J. Siegel, P. Saukko, G. Knupfer (Editors), Encyclopedia of Forensic Sciences, Academic Press, Oxford, 2000.

[15] C.J. Polson, J. Crim. Law. Criminol. (1931), 41 (1951) 690-704.

[16] C. Sengupta, Imprint of the Raj: how fingerprinting was born in colonial India, Macmillan, London, 2003.

[17] G.S. Sodhi, J. Kaur, Curr. Sci., 88 (2005) 185-191.

[18] J. Berry, D.A. Stoney, History and Development of Fingerprinting in: H.C. Lee, R.E. Gaensslen (Editors), Advances in Fingerprint Technology, Second Edition, CRC Press, Boca Raton, 2001.

[19] H. Faulds, Nature, 22 (1880) 605.

[20] H.C. Lee, R.E. Gaensslen, Methods of Latent Fingerprint Development in: H.C. Lee, R.E. Gaensslen (Editors), Advances in Fingerprint Technology, Second Edition, CRC Press, Boca Raton, 2001.

[21] S.K. Bramble, J.S. Brennan, FINGERPRINTS (DACTYLOSCOPY): Chemistry of Print Residue in: J. Siegel, P. Saukko, G. Knupfer (Editors), Encyclopedia of Forensic Sciences, Academic Press, Oxford, 2000, p. 862869.

[22] P.H. Gitlitz, F.W. Sunderman, Jr., D.C. Hohnadel, Clin. Chem., 20 (1974) 1305-1312.

[23] S.W. Hier, T. Cornbleet, O. Bergeim, J. Biol. Chem., 166 (1946) 327-333.

[24] N. Liappis, H. Hungerland, Am. J. Clin. Nutr., 25 (1972) 661-663.

[25] N. Liappis, H. Hungerland, Clinica Chimica Acta, 48 (1973) 233-236. 
[26] M. Stoilovic, C. Lennard, AFP Workshop Manual: Fingerprint Detection \& Enhancement, Forensic Services, Australian Federal Police, Canberra, 2006.

[27] S. Hardwick, D.F. Hewlett, T. Kent, V. Sears, FINGERPRINTS

(DACTYLOSCOPY): Sequential Treatment and Enhancement in: J. Siegel, P. Saukko, G. Knupfer (Editors), Encyclopedia of Forensic Sciences, Academic Press, Oxford, 2000.

[28] S. Wiesner, E. Springer, Y. Sasson, J. Almog, J. Forensic Sci., 46 (2001) 1082-1084.

[29] H. Bandey, Fingerprint Development and Imaging Newsletter: Special Edition, 2004, http://scienceandresearch.homeoffice.gov.uk/hosdb/publications/fingerprintpublications/54-04-The-Powders-Process-s1.pdf, accessed 25 March 2009.

[30] C. Conn, G. Ramsay, C. Roux, C. Lennard, Forensic Sci. Int., 116 (2001) 117123.

[31] G. Payne, B. Reedy, C. Lennard, B. Comber, D. Exline, C. Roux, Forensic Sci. Int., 150 (2005) 33-51.

[32] C. Roux, N. Jones, C. Lennard, M. Stoilovic, J. Forensic Sci., 45 (2000) 761769.

[33] M. Stoilovic, C. Lennard, C. Wallace-Kunkel, C. Roux, J. Forensic Ident., 57 (2007) 4-18.

[34] C. Wallace-Kunkel, C. Lennard, M. Stoilovic, C. Roux, Forensic Sci. Int., 168 (2007) 14-26.

[35] C. Wallace-Kunkel, C. Roux, C. Lennard, M. Stoilovic, J. Forensic Ident., 54 (2004) 687 - 705.

[36] D.E. Bicknell, R.S. Ramotowski, J. Forensic Sci., 53 (2008) 1108-1116.

[37] L. Schwarz, I. Klenke, J. Forensic Sci., 52 (2007) 649-655.

[38] W.B. Corson, J.E. Lawson, K.E. Kuhn, J. Forensic Ident., 41 (1991) 437-441.

[39] G.C. Goode, J.R. Morris, in C.A. Beck (Editor), UK Unclassified: Atomic Weapons Research Establishment, 1983.

[40] N. Masters, R. Morgan, E. Shipp, J. Forensic Ident., 41 (1991) 3-10.

[41] R. Jelly, S.W. Lewis, C. Lennard, K.F. Lim, J. Almog, Chem. Commun. (Camb), (2008) 3513-3515.

[42] H.J. Kobus, M. Stoilovic, R.N. Warrener, Forensic Sci. Int., 22 (1983) 161170.

[43] B.E. Dalrymple, J.M. Duff, E.R. Menzel, J. Forensic Sci., 22 (1977) 106-115.

[44] D.W. Herod, E.R. Menzel, J. Forensic Sci., 27 (1982) 513 - 518.

[45] M. Stoilovic, R.N. Warrener, H.J. Kobus, Forensic Sci. Int., 24 (1984) 279284.

[46] C. Champod, N. Egli, P.A. Margot, in Review Papers of the 14th Interpol International Forensic Science Symposium, Interpol - Lyon, 2004.

[47] D.L. Exline, C. Wallace, C. Roux, C. Lennard, M.P. Nelson, P.J. Treado, J. Forensic Sci., 48 (2003) 1047-1053.

[48] D. Wilkinson, D. Rumsby, B. Babin, M. Merritt, J. Marsh, Identification Canada, 27 (2004) 10 - 24.

[49] J. Almog, V.G. Sears, E. Springer, D.F. Hewlett, S. Walker, S. Wiesner, R. Lidor, E. Bahar, J. Forensic Sci., 45 (2000) 538-544.

[50] H.J. Kobus, P.E. Pigou, S. Jahangiri, B. Taylor, J. Forensic Sci., 47 (2002) 254-259.

[51] D.B. Hauze, O. Petrovskaia, B. Taylor, M.M. Joullie, R. Ramotowski, A.A. Cantu, J. Forensic Sci., 43 (1998) 744-747. 
[52] D.B. Hansen, M.M. Joullie, Chem. Soc. Rev., 34 (2005) 408-417.

[53] M. Friedman, J. Agric. Food Chem., 52 (2004) 385-406.

[54] D.J. McCaldin, Chem. Rev., 60 (1960) 39-51.

[55] M. Friedman, L. David Williams, Bioorganic Chemistry, 3 (1974) 267-280.

[56] R. Grigg, J.F. Malone, T. Mongkolaussavaratana, S. Thianpatanagul, J. Chem. Soc. Chem. Commun., (1986) 421-422.

[57] O. Petrovskaia, B.M. Taylor, D.B. Hauze, P.J. Carroll, M.M. Joullie, J. Org. Chem., 66 (2001) 7666-7675.

[58] N.D.K. Petraco, G. Proni, J.J. Jackiw, A.M. Sapse, J. Forensic Sci., 51 (2006) 1267-1275.

[59] R. Saferstein, Criminalistics: an introduction to forensic science, Prentice Hall, Upper Saddle River, N.J., 2007.

[60] D.A. Skoog, D.M. West, F.J. Holler, Fundamentals of Analytical Chemistry, Saunders College Publishing, New York, 1988.

[61] C.J. Lennard, P.A. Margot, M. Sterns, R.N. Warrener, J. Forensic Sci., 32 (1987) 597 - 605.

[62] P.J. Davies, M.R. Taylor, K.P. Wainwright, Acta Crystallographica Section C, 51 (1995) 1802-1805.

[63] P.J. Davies, H.J. Kobus, M.R. Taylor, K.P. Wainwright, J. Forensic Sci., 40 (1995) 565-569.

[64] D. Hewlett, V.G. Sears, J. Forensic Ident., 47 (1997) 287-299.

[65] D. Hewlett, V.G. Sears, S. Suzuki, J. Forensic Ident., 47 (1997) 300-306.

[66] P.J. Lamothe, P.G. McCormick, Anal. Chem., 44 (1972) 821-825.

[67] A.V. Petruncio, J. Forensic Ident., 50 (2000) 462-469.

[68] R.R. Hark, D.B. Hauze, O. Petrovskaia, M.M. Joullie, Can. J. Chem., 79 (2001) 1632-1654.

[69] J. Druey, P. Schmidt, Helvetica Chimica Acta, 33 (1950) 1080-1087.

[70] C.A. Pounds, M. Phil, R. Grigg, T. Mongkolaussavaratana, J. Forensic Sci., 35 (1990) 169-175.

[71] R. Grigg, T. Mongkolaussavaratana, C.A. Pounds, S. Sivagnanam, Tetrahedron Letters, 31 (1990) 7215 - 7218.

[72] M. Stoilovic, Forensic Sci. Int., 60 (1993) 141-153.

[73] D. Wilkinson, Forensic Sci. Int., 109 (2000) 87-103.

[74] A.A. Cantu, D.A. Leben, M.M. Joullie, R.J. Heffner, R.R. Hark, J. Forensic Ident., 43 (1993) 44-62.

[75] S. Hardwick, T. Kent, V. Sears, P. Winfield, Fingerprint Whorld, 19 (1993) 65-69.

[76] C. Didierjean, M.-H. Debart, F. Crispino, The Print, 15 (1999) 6-8.

[77] S. Merrick, S.J. Gardner, V.G. Sears, D.F. Hewlett, J. Forensic Ident., 52 (2002) 595-605.

[78] R.M. Bratton, J.A. Juhala, J. Forensic Ident., 45 (1995) 169-172.

[79] R. Ramotowski, A.A. Cantu, M.M. Joullie, O. Petrovskaia, Fingerprint Whorld, 23 (1997) 131-140.

[80] B.M. Taylor, M.M. Joullie, Tetrahedron, 54 (1998) 15121-15126.

[81] I.M. Alaoui, E.R. Menzel, M. Farag, K.H. Cheng, R.H. Murdock, Forensic Sci. Int., 152 (2005) 215-219.

[82] S.J. Gardner, D.F. Hewlett, J. Forensic Sci., 48 (2003) 1288-1292.

[83] M. Azoury, A. Zamir, C. Oz, S. Wiesner, J. Forensic Sci., 47 (2002) 586-588.

[84] M. Azoury, R. Gabbay, D. Cohen, J. Almog, J. Forensic Sci., 48 (2003) 564570 . 
[85] J.T. Stimac, J. Forensic Ident., 53 (2003) 265-271.

[86] S.E. Russell, G.L. John, S.L. Naccarato, J. Forensic Ident., 58 (2008) 182-192.

[87] D. Wilkinson, Forensic Sci. Int., 114 (2000) 123-132.

[88] M. Friedman, C.W. Sigel, Biochemistry, 5 (1966) 478-485.

[89] D. Wilkinson, E. Mackenzie, C. Leech, D. Mayowski, S. Bertrand, T. Walker, Identification Canada, 26 (2003) 8 - 18.

[90] X. Spindler, M. Stoilovic, C. Lennard, A. Lennard, J. Forensic Ident., 59 (2009) 308-324.

[91] J. Almog, Y. Cohen, M. Azoury, T.R. Hahn, J. Forensic Sci., 49 (2004) 255257.

[92] M.F. Butler, Y.F. Ng, P.D.A. Pudney, J. Polym. Sci. [A1], 41 (2003) 39413953.

[93] Y.S. Paik, C.M. Lee, M.H. Cho, T.R. Hahn, J. Agric. Food Chem., 49 (2001) 430-432.

[94] T.R. Tsai, T.Y. Tseng, C.F. Chen, T.H. Tsai, Journal of Chromatography A, 961 (2002) 83-88.

[95] C. Djerassi, J.D. Gray, F.A. Kincl, J. Org. Chem., 25 (1960) 2174-2177.

[96] C. Djerassi, T. Nakano, A.N. James, L.H. Zalkow, E.J. Eisenbraun, J.N. Shoolery, J. Org. Chem., 26 (1961) 1192-1206.

[97] S. Fujikawa, Y. Kukui, K. Koga, J.-i. Kumada, J. Ferment. Technol., 65 (1987) 419-424.

[98] F.L. Mi, S.S. Shyu, C.K. Peng, J. Polym. Sci. [A1], 43 (2005) 1985-2000.

[99] F.L. Mi, Biomacromolecules, 6 (2005) 975-987.

[100] H.W. Sung, D.M. Huang, W.H. Chang, R.N. Huang, J.C. Hsu, J. Biomed. Mater. Res., 46 (1999) 520-530.

[101] C.H. Yao, B.S. Liu, C.J. Chang, S.H. Hsu, Y.S. Chen, Materials Chemistry and Physics, 83 (2004) 204-208.

[102] H.W. Sung, D.M. Huang, W.H. Chang, L.L.H. Huang, C.C. Tsai, I.L. Liang, Journal of Biomaterials Science-Polymer Edition, 10 (1999) 751-771.

[103] W.H. Chang, Y. Chang, P.H. Lai, H.W. Sung, Journal of Biomaterials Science-Polymer Edition, 14 (2003) 481-495.

[104] C.H. Yao, B.S. Liu, S.H. Hsu, Y.S. Chen, Biomaterials, 26 (2005) 3065-3074.

[105] Y.S. Chen, J.Y. Chang, C.Y. Cheng, F.J. Tsai, C.H. Yao, B.S. Liu, Biomaterials, 26 (2005) 3911-3918.

[106] S. Fujikawa, S. Nakamura, K. Koga, Agric. Biol. Chem., 52 (1988) 869-870.

[107] W.H. Chang, Y. Chang, Y.C. Chen, H.W. Sung, Artif. Cells Blood Substit. Immobil. Biotechnol., 32 (2004) 243-262.

[108] S.W. Lee, J.M. Lim, S.H. Bhoo, Y.S. Paik, T.R. Hahn, Anal. Chim. Acta, 480 (2003) 267-274.

[109] R. Touyama, Y. Takeda, K. Inoue, I. Kawamura, M. Yatsuzuka, T. Ikumoto, T. Shingu, T. Yokoi, H. Inouye, Chem. Pharm. Bull., 42 (1994) 668-673.

[110] R. Touyama, K. Inoue, Y. Takeda, M. Yatsuzuka, T. Ikumoto, N. Moritome, T. Shingu, T. Yokoi, H. Inouye, Chem. Pharm. Bull., 42 (1994) 1571-1578.

[111] Y.K. Fazendin, A Preliminary Investigation into the Reaction of Genipin with Ethylamine: Separation and Characterisation of the Blue Polymeric Products, BSc (Chemical Sciences) (Honours) thesis, Deakin University, 2007.

[112] A.F. Nikkels, F. Henry, G.E. Pierard, J. Eur. Acad. Dermatol. Venereol., 15 (2001) 140-142.

[113] R. Petkewich, Chem. Eng. News, 84 (2006) 28. 
[114] G.J. Nohynek, R. Fautz, F. Benech-Kieffer, H. Toutain, Food and Chemical Toxicology, 42 (2004) 517-543.

[115] S. Spyroudis, Molecules, 5 (2000) 1291-1330.

[116] K.O. Eyong, G.N. Folefoc, V. Kuete, V.P. Beng, K. Krohn, H. Hussain, A.E. Nkengfack, M. Saeftel, S.R. Sarite, A. Hoerauf, Phytochemistry, 67 (2006) 605-609.

[117] L. Han, X.S. Huang, H.M. Dahse, U. Moellmann, H.Z. Fu, S. Grabley, I. Sattler, W.H. Lin, J. Nat. Prod., 70 (2007) 923-927.

[118] K. Bock, N. Jacobsen, B. Terem, J. Chem. Soc. Perkin Trans. I, (1986) 659664.

[119] F.J. Bullock, J.F. Tweedie, D.D. McRitchie, J. Chem. Soc. C, (1969) 17991803.

[120] K.Y. Chu, J. Griffiths, J. Chem. Soc. Perkin Trans. I, (1978) 1083-1087.

[121] K.Y. Chu, J. Griffiths, J. Chem. Res. Synop., (1978) 180-181.

[122] K.Y. Chu, J. Griffiths, J. Chem. Soc. Perkin Trans. I, (1979) 696-701.

[123] G. Greenbuckley, J. Griffiths, J. Chem. Soc. Perkin Trans. I, (1979) 702-707.

[124] E. Malamidou-Xenikaki, S. Spyroudis, M. Tsanakopoulou, J. Org. Chem., 68 (2003) 5627-5631.

[125] C. Pachatouridis, E.A. Couladouros, V.P. Papageorgiou, M. LiakopoulouKyriakides, Letters in Peptide Science, 5 (1998) 259-262.

[126] A. Sarhan, A.M.K. El-Dean, M.I. Abdel-Monem, Monatsh. Chem., 129 (1998) 205-212.

[127] M.W. Singh, A. Karmakar, N. Barooah, J.B. Baruah, Beilstein J. Org. Chem., 3 (2007) 10-15.

[128] K. Spagou, E. Malamidou-Xenikaki, S. Spyroudis, Molecules, 10 (2005) 226237.

[129] W. Troll, The Journal of Biological Chemistry, 202 (1953) 479-486.

[130] E.G. Frame, J.A. Russell, A.E. Wilhelmi, The Journal of Biological Chemistry, 149 (1943) 255-270.

[131] N.H. Furman, G.H. Morrison, A.F. Wagner, Analtical Chemistry, 22 (1950) 1561-1562.

[132] J. Saurina, S. Hernandezcassou, R. Tauler, Anal. Chem., 67 (1995) 37223726.

[133] J. Saurina, S. Hernandez-Cassou, R. Tauler, Anal. Chim. Acta, 335 (1996) 4149.

[134] J. Saurina, S. HernandezCassou, R. Tauler, Anal. Chem., 69 (1997) 23292336.

[135] J.R. Rees, A. Pirie, Biochem. J., 102 (1967) 853-863.

[136] B. Hartzell-Baguley, R.E. Hipp, N.R. Morgan, S.L. Morgan, Journal of Chemical Education, 84 (2007) 689-691.

[137] N.E. Jones, L.M. Davies, J.S. Brennan, S.K. Bramble, J. Forensic Sci., 45 (2000) 1286-1293.

[138] C. Ricci, P. Phiriyavityopas, N. Curum, K.L.A. Chan, S. Jickells, S.G. Kazarian, Applied Spectroscopy, 61 (2007) 514-522.

[139] A. Richmond-Aylor, S. Bell, P. Callery, K. Morris, J. Forensic Sci., 52 (2007) 380-382. 


\section{Table legends}

Table 1. Human skin secretory glands [11].

Table 2. Summary of main constituents of eccrine and sebaceous skin secretions $[3,12,21]$.

Table 3. Major amino acids found in a single wet thumb print [6].

Table 4. Conditions for observing photoluminescence of latent fingermarks treated with amino acid reagents [26].

\section{Figure legends}

Figure 1: Latent fingermarks treated with the amino acid sensitive reagent lawsone. Images (a) and (b) were taken with a Pentax K10 digital SLR, $50 \mathrm{~mm}$ focal length, ISO 100. (a) photoluminescence mode (excitation with a Polilight PL 500 at 590nm and viewed through a Wratten NA29 filter, shutter speed $6.0 \mathrm{~s}$, aperture f2.8). (b) taken under white light (shutter speed 1/125 s, aperture f4), (c) acquired using a Poliview digital imaging system (Rofin, Australia) with excitation at $590 \mathrm{~nm}$, viewed through a $650 \mathrm{~nm}$ interference filter with a $1 \mathrm{~s}$ exposure time. Reference [41] reproduced by permission of The Royal Society of Chemistry.

Figure 2: (a) Relative absorption spectrum of Ruhemann's purple and its complexes with zinc and cadmium (b) Recommended bandpass filters for observation in the absorption mode for the zinc complex (c) Recommended bandpass filters for observation in the absorption mode for the cadmium complex [3], used by permission.

Figure 3: Structures of ninhydrin analogues. The commonly-used names are given in the figure for consistency with previous work; the systematic names are listed here for the convenience of the reader: benzo[f]ninhydrin $(1 H$-cyclopenta[b]naphthalene1,2,3-trione), 5-methoxyninhydrin (5-methoxy-1H-indene-1,2,3-trione), 5(methylthio)ninhydrin (5-(methylthio)-1H-indene-1,2,3-trione), 5-aminoninhydrin (5amino-1H-indene-1,2,3-trione), 5-dimethylninhydrin (5-(dimethylamino)- $1 \mathrm{H}$-indene- 
1,2,3-trione), 5,6-dimethoxy-1,2-indanedione $\quad$ (5,6-dimethoxy-1H-indene-1,2(3H)dione).

Figure 4: Structures of genipin and lawsone.

Figure 5: Proposed structures of the yellow and brownish-red (A-I) intermediates $[109,110]$.

Figure 6: Proposed resonance structures of (a) Genipocyanin; (b) a dimer from Genipin and a primary amine $(\mathrm{R}=$ protein $)$ [106].

\section{Scheme legends}

Scheme 1. (a) The reaction mechanism of ninhydrin with amino acids to form Ruhemann's purple $[2,52,53,55]$. (b) The reaction of Ruhemann's purple with metal salts to form a complex ion $[61,63]$.

Scheme 2. Proposed reaction mechanism of DFO and an amino acid $[30,71,73]$.

Scheme 3. Proposed reaction mechanism of 1,2-indanedione and $\alpha$-amino acids [57].

Scheme 4. Suggested reaction mechanism of lawsone and amino acids [41]. 
Table 1: Human skin secretory glands

\begin{tabular}{|c|c|c|c|}
\hline Types of Glands & Secretion types & Body Distribution & Role of Gland \\
\hline Sebaceous & Sebum (lipids) & $\begin{array}{lr}\text { Typically } & \text { localised } \\
\text { to } & \text { regions } \\
\text { containing } & \text { hair } \\
\text { follicles } & \end{array}$ & $\begin{array}{l}\text { Inhibits the growth of } \\
\text { bacteria, lubricates and } \\
\text { protects the keratin of the } \\
\text { hair shaft and conditions } \\
\text { the surrounding skin }\end{array}$ \\
\hline \multicolumn{4}{|c|}{ Sweat (sudiferous) glands } \\
\hline $\begin{array}{l}\text { Eccrine } \\
\text { (merocrine) }\end{array}$ & Sweat (aqueous) & $\begin{array}{l}\text { Entire body, highly } \\
\text { concentrated on the } \\
\text { palms of the hands } \\
\text { and soles of the feet }\end{array}$ & $\begin{array}{l}\text { Cooling the surface of the } \\
\text { skin to reduce body } \\
\text { temperature, excretion of } \\
\text { water, electrolytes and } \\
\text { metabolites, protection } \\
\text { from environmental } \\
\text { hazards }\end{array}$ \\
\hline Apocrine & Sweat (aqueous) & $\begin{array}{l}\text { Associated with } \\
\text { hair follicles around } \\
\text { the axillary regions. } \\
\text { In particular, the } \\
\text { armpits, groin and } \\
\text { chest. }\end{array}$ & Scent glands (pheromones) \\
\hline
\end{tabular}


Table 2: Summary of main constituents of eccrine and sebaceous skin secretions

\begin{tabular}{lll}
\hline Secretion & Constituents & \\
\hline \multirow{2}{*}{ Eccrine } & Organic & Inorganic \\
\cline { 2 - 3 } & Amino acids & Water $(>98 \%)$ \\
Proteins & Chloride \\
Urea & Metal ions $\left(\mathrm{Na}^{+}, \mathrm{K}^{+}, \mathrm{Ca}^{2+}\right)$ \\
Uric acid & Sulfate \\
Lactic acid & Phosphate \\
Sugars & Hydrogen carbonate \\
Creatinine & Ammonia \\
Choline & \\
Sebaceous & Glycerides & \\
& Fatty acids & \\
Wax esters & \\
Squalene & \\
Sterol esters & \\
Sterols & \\
\hline
\end{tabular}


Table 3: Major amino acids found in a single wet thumb print

\begin{tabular}{ll}
\hline Amino acid & Amount $(\mu \mathrm{mol})$ \\
\hline serine & 0.106 \\
glycine & 0.071 \\
ornithine & 0.034 \\
alanine & 0.029 \\
aspartic acid & 0.023 \\
threonine & 0.018 \\
histidine & 0.018 \\
valine & 0.013 \\
proline & 0.011 \\
leucine & 0.011 \\
\hline
\end{tabular}


Table 4: Conditions for observing photoluminescence of latent fingermarks treated with amino acid reagents

\begin{tabular}{|c|c|c|}
\hline Reagent & $\begin{array}{l}\text { Excitation Band (Polilight } \\
\text { PL 500) }\end{array}$ & $\begin{array}{l}\text { Viewing and recording } \\
\text { conditions (goggles and } \\
\text { camera barrier filters) }\end{array}$ \\
\hline $\begin{array}{l}\text { Ninhydrin post-treated } \\
\text { with zinc chloride }\end{array}$ & $490 \mathrm{~nm}$ & $\begin{array}{l}\text { Orange goggles, band-pass } \\
\text { IF565 or long pass } \\
\text { KV550/OG } 550\end{array}$ \\
\hline $\begin{array}{l}\text { 1,8-Diazaflouren-9-one } \\
\text { (DFO) }\end{array}$ & $505 \mathrm{~nm}$ & $\begin{array}{l}\text { Orange goggles, band-pass } \\
\text { IF565 or long pass } \\
\text { KV550/OG } 550\end{array}$ \\
\hline & $530 \mathrm{~nm}$ & $\begin{array}{l}\text { Red goggles, long pass } \\
\text { OG590/IF590 }\end{array}$ \\
\hline & $555 \mathrm{~nm}$ & $\begin{array}{l}\text { Red goggles, band-pass } \\
\text { IF600 or IF610 }\end{array}$ \\
\hline $\begin{array}{l}\text { 1,2-Indanedione }- \text { Zinc } \\
\text { (IND-Zn) }\end{array}$ & $505 \mathrm{~nm}$ & $\begin{array}{l}\text { Orange goggles, band-pass } \\
\text { IF565 or long pass } \\
\text { KV550/OG550 }\end{array}$ \\
\hline Genipin & $555 \mathrm{~nm}$ & $\begin{array}{l}\text { Red goggles, band-pass } \\
\text { IF600 or IF610 }\end{array}$ \\
\hline Lawsone & $590 \mathrm{~nm}$ & $\begin{array}{l}\text { Red goggles, } \\
\text { NA29 }\end{array}$ \\
\hline
\end{tabular}


Figure 1 (a)

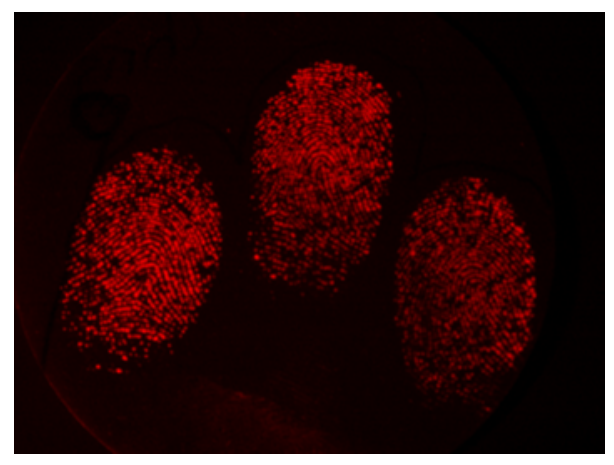

Figure 1 (b)

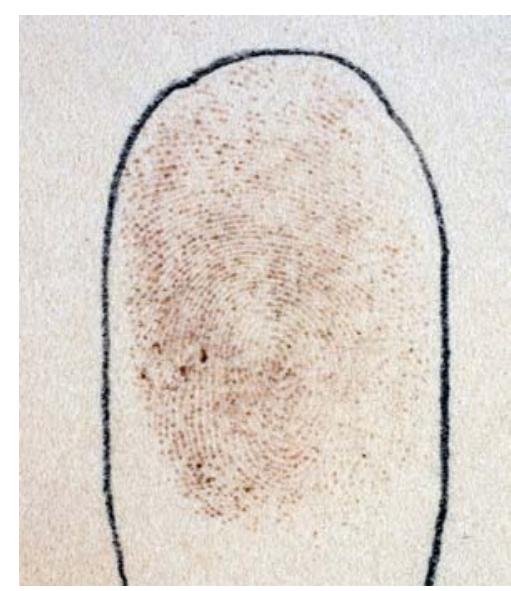

Figure 1 (c)

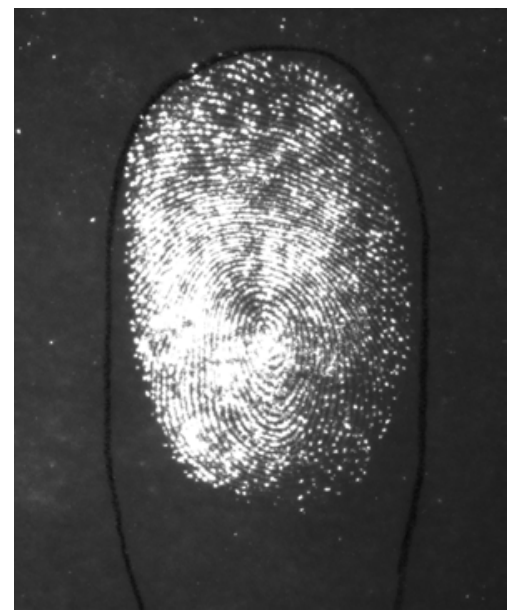


Figure 2

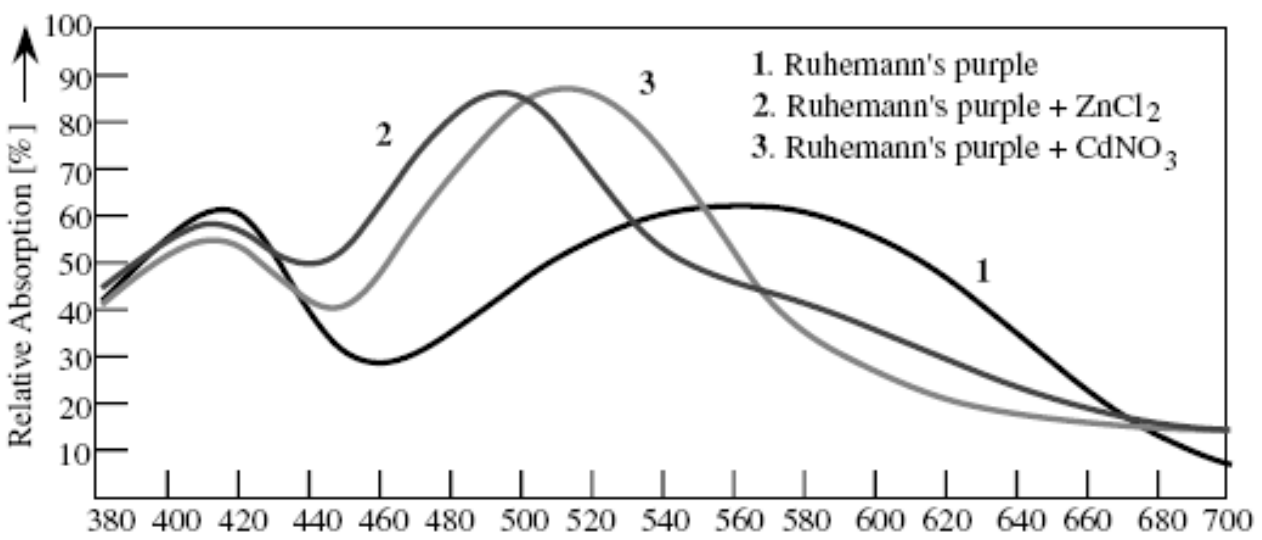

(A)

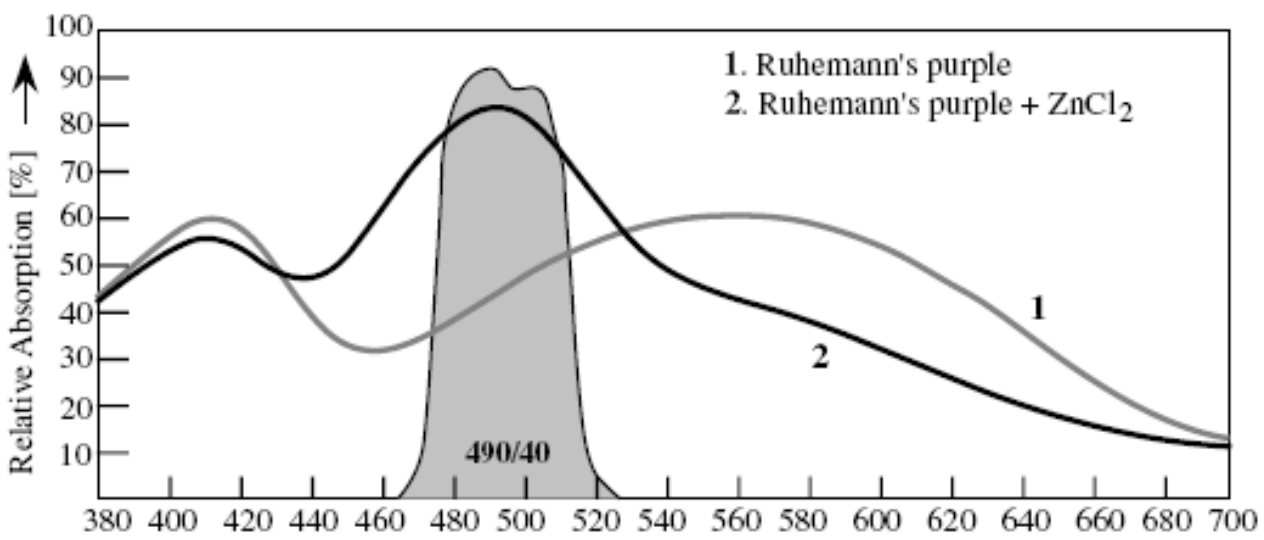

(B)

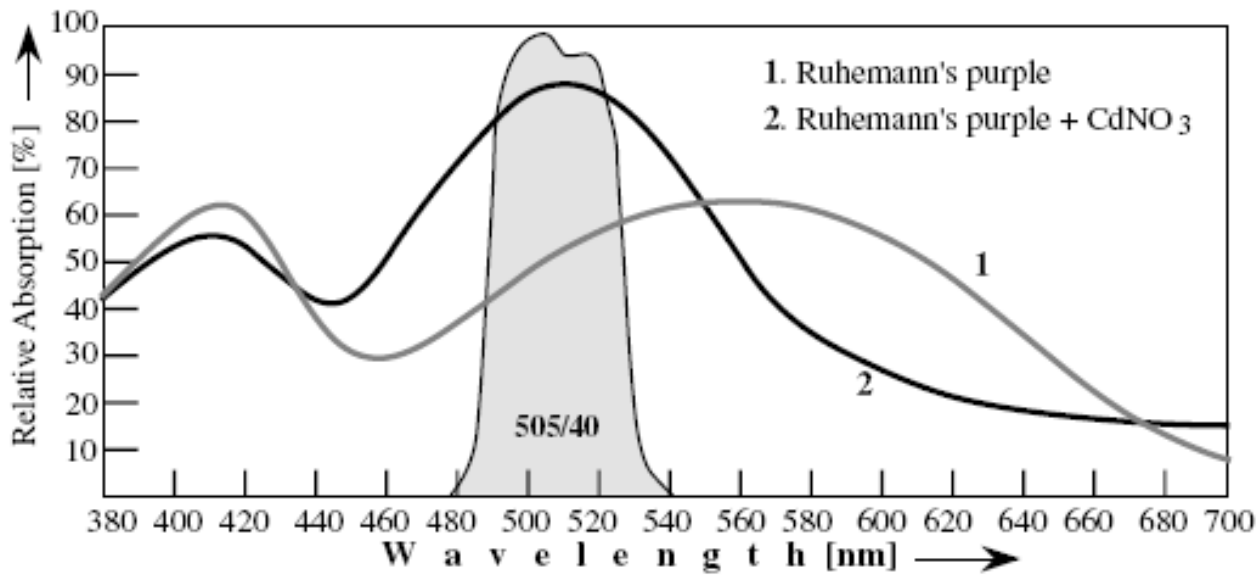

(C) 
Figure 3<smiles>O=c1c(=O)c2cc3ccccc3cc2c1=O</smiles>

benzo[f]ninhydrin<smiles>Nc1ccc2c(=O)c(=O)c(=O)c2c1</smiles>

5-aminoninhydrin<smiles>COc1ccc2c(=O)c(=O)c(=O)c2c1</smiles>

5-methoxyninhydrin<smiles>O=C1Cc2ccccc2C1=O</smiles>

1,2-indanedione<smiles>CSc1ccc2c(=O)c(=O)c(=O)c2c1</smiles>

5-(methylthio)ninhydrin<smiles>O=C1c2ncccc2-c2cccnc21</smiles>

1,8-diazafluoren-9-one (DFO)<smiles>CN(C)c1ccc2c(=O)c(=O)c(=O)c2c1</smiles><smiles>COc1cc2c(cc1OC)C(=O)C(=O)C2</smiles>

5-(N,N-dimethylamino)ninhydrin 5,6-dimethoxy-1,2-indanedione

\section{Figure 4}<smiles>COC(=O)C1=COC(O)C2C(CO)=CCC12</smiles>

Genipin<smiles>O=C1C=C(O)C(=O)c2ccccc21</smiles>

Lawsone 
Figure 5
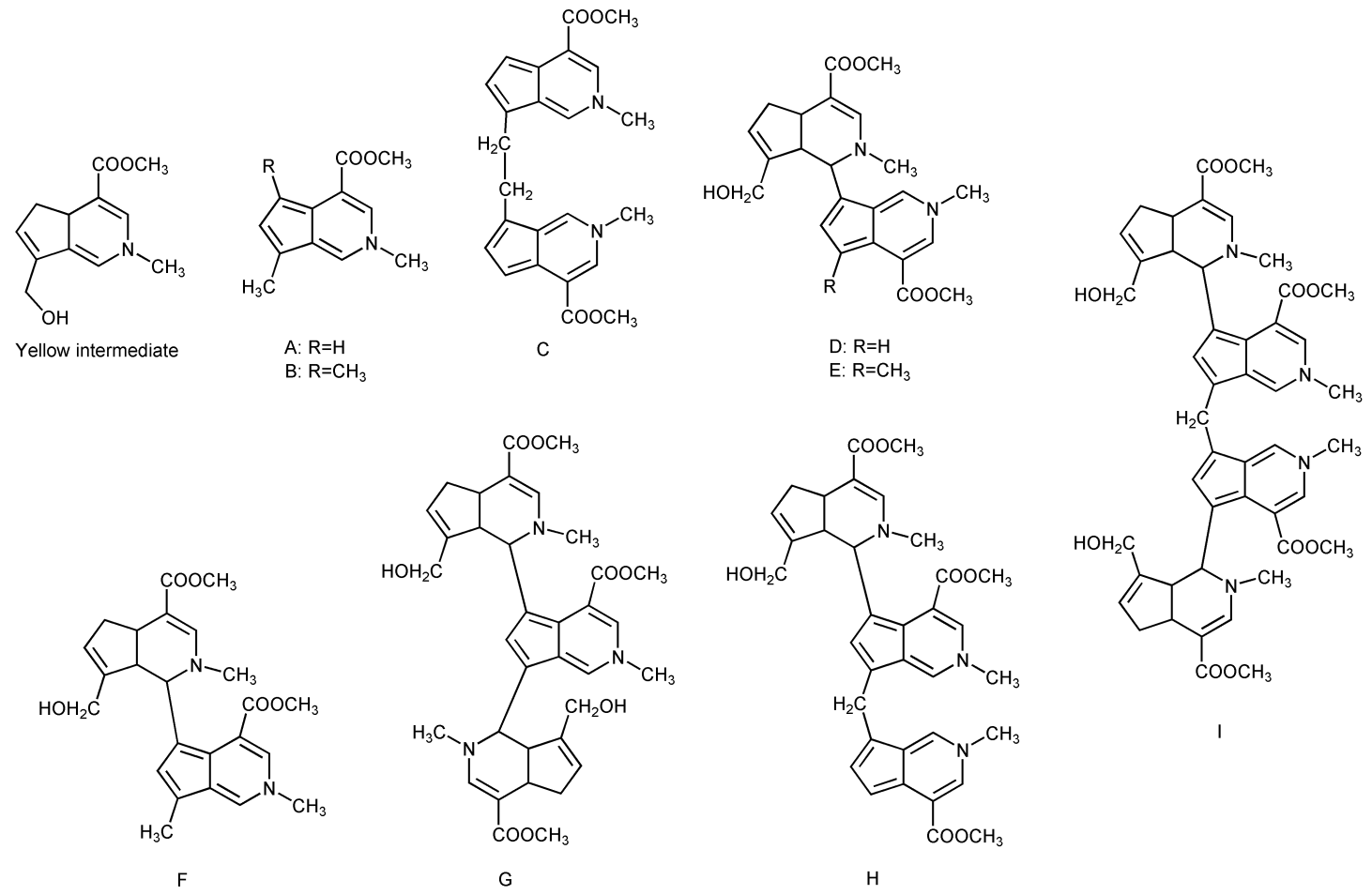

Figure 6

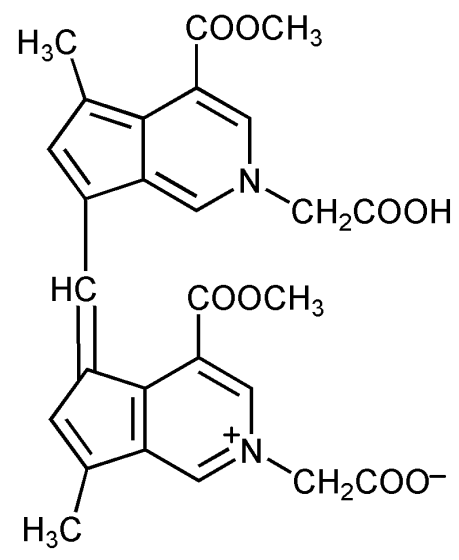

a.

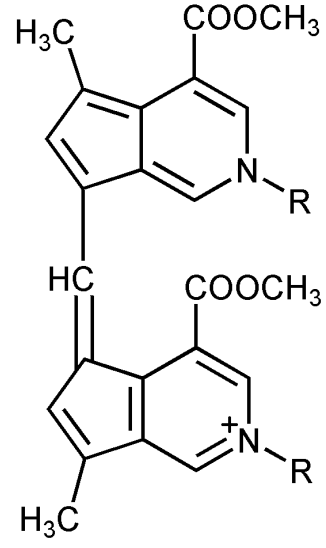

b. 


\section{Scheme 1}

a)

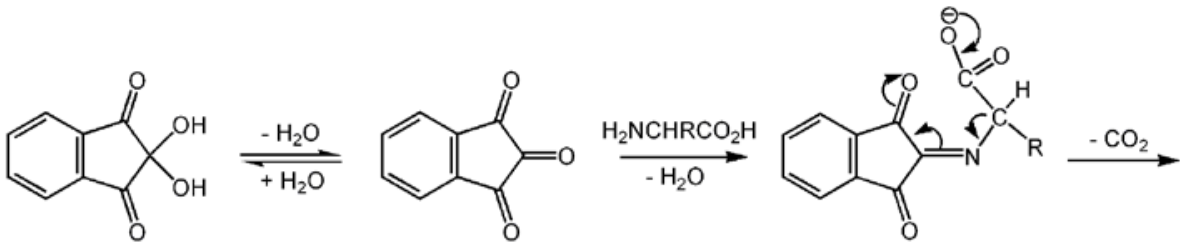

ninhydrin

indanetrione<smiles>[R]C=N[C@H]1C(=O)c2ccc(C)cc2C1=O</smiles>

$\underset{\mathrm{RCHO}}{\stackrel{\mathrm{H}_{2} \mathrm{O}, \mathrm{H}^{+}}{\longrightarrow}}$

(II)<smiles>O=C1C(N=c2c(=O)c3ccccc3c2=O)=C([O-])c2ccccc21</smiles>

Ruhemann's Purple

b)

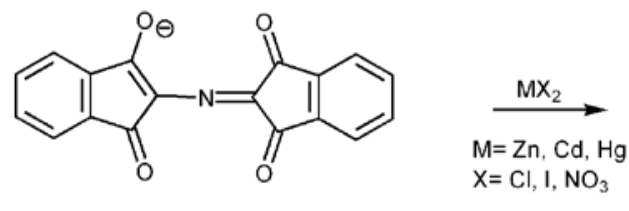

Ruhemann's purple

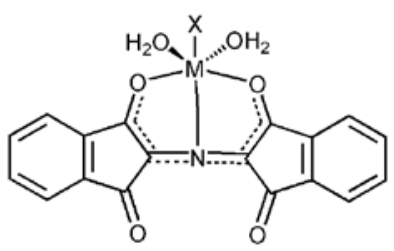

Ruhemann's purple metal ion complex

\section{Scheme 2}

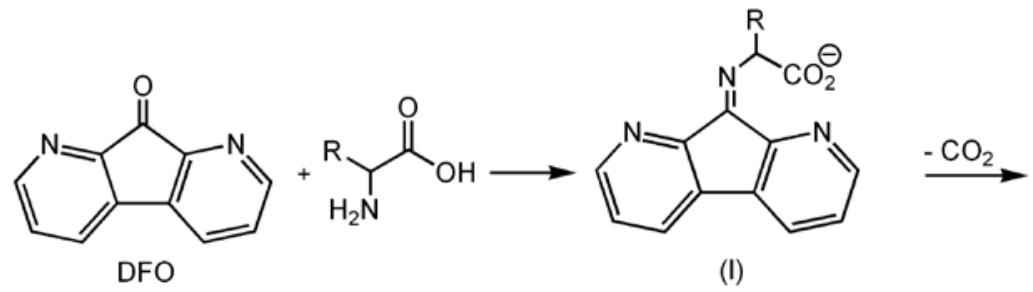<smiles>[R]C=NC1c2ncccc2-c2ccc(C=[R]O)nc21</smiles>

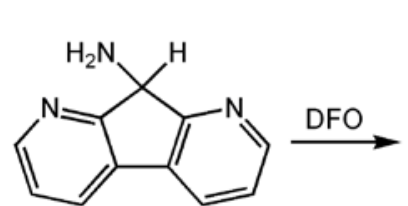

(II)

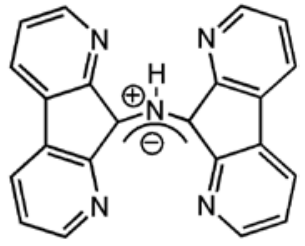

(III) 


\section{Scheme 3}

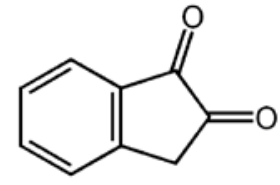

$\mathrm{H}_{2} \mathrm{NCHRCO}_{2} \mathrm{H}$

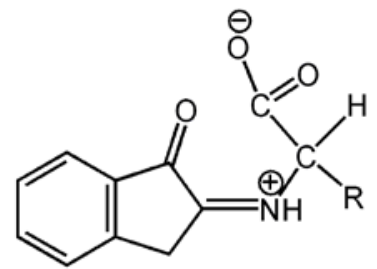

1,2-indanedione

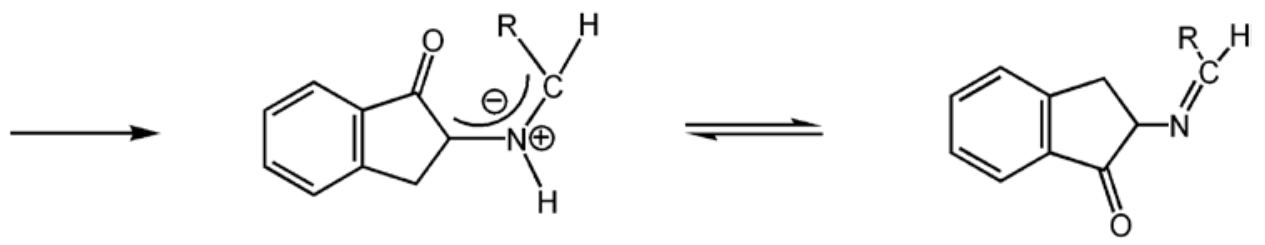

(I)

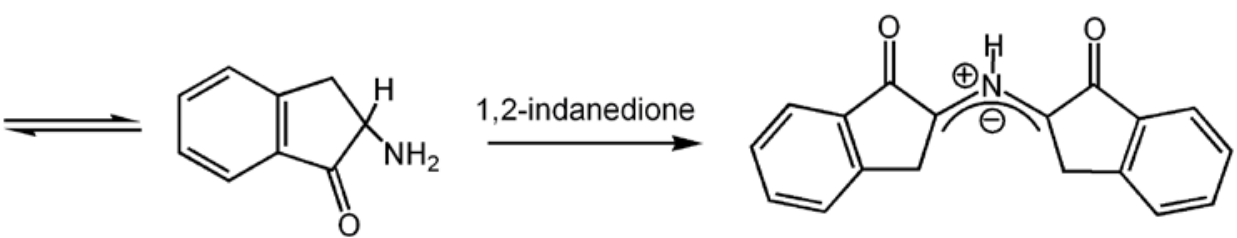

(II)

(III)

Scheme 4

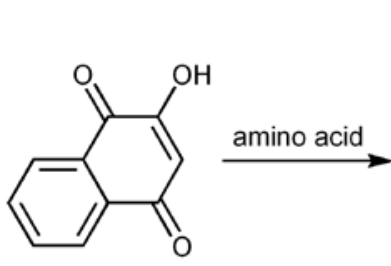

lawsone

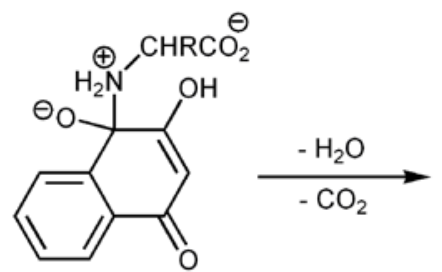

lawsone

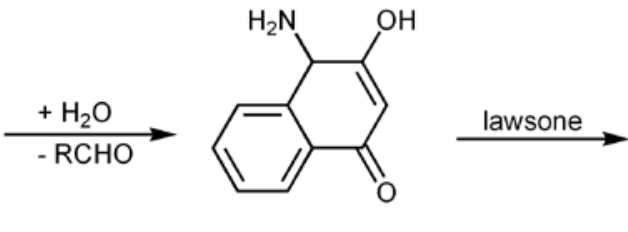

amine derivative (I)

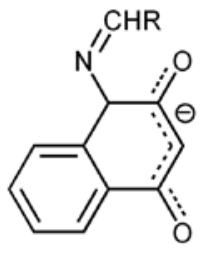

imine intermediate

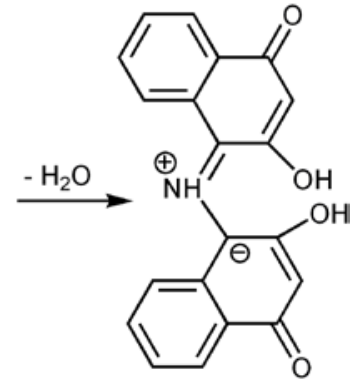

